A Theory of Behavioral Contrast

Peter R. Killeen

Arizona State University

This is the pre-peer reviewed version of the following article:

Killeen, P. R. (2014). A theory of behavioral contrast. Journal of the Experimental Analysis of Behavior, 102 (102), 3. doi: 10.1002/jeab.107

which has been published in final form at http://is.gd/3CK8y5 .

Killeen@asu.edu 


\begin{abstract}
The reinforcers that maintain target instrumental responses also reinforce other responses that compete with them for expression. This competition, and its imbalance at points of transition between different schedules of reinforcement, causes behavioral contrast. The imbalance is caused by differences in the rates at which different responses come under the control of component stimuli. A model for this theory of behavioral contrast is constructed by expanding the coupling coefficient of MPR (Killeen, 1994). The coupling coefficient gives the degree of association of a reinforcer with the target response relative to other competing responses. Competing responses, often identified as interim or adjunctive or superstitious behavior, are intrinsic to reinforcement schedules, especially interval schedules. In addition to that base-rate of competition, additional competing responses may spill over from the prior component, causing initial contrast; and they may be modulated by conditioned reinforcement or punishment from stimuli associated with subsequent component change, causing terminal contrast. A formalization of these hypotheses employed (a) a hysteresis model of off-target responses giving rise to initial contrast, and (b) a competing traces model of the suppression or enhancement of ongoing competitive responses by signals of following-schedule transition. The theory was applied to transient contrast, the following schedule effect, and the component duration effect.
\end{abstract}

Keywords: Behavioral contrast, competing responses, MPR 


\section{A Theory of Behavioral Contrast}

Action at a distance is a bete noire for many scientists who spend their careers seeking mechanisms to mediate events that are disjoint in space or time. The young Newton disavowed recourse to unobservable hypothetical constructs (Westfall, 1971). But gravity epitomizes such a construct. In response to critics who noted the absence of mechanism in Principia, he simply asserted that he did not make hypotheses [about the mechanism]. He retreated, not from the construct, but from the demand to reify it. General relativity eventually provided a mechanism in the warping of space around massive bodies. Physicists discarded the luminiferous ether, but installed electromagnetic fields in its place. Feynman labored to rid physics of fields as anything other than book-keeping formulations (Mehra, 1994), but in the end he failed. The experimental validation of the Higgs field was recently greeted with universal applause. Nature, apparently, abhors a vacuum.

Action at a distance is also a problem for behavioral psychologists. A modern cottage industry in our discipline is the study of delay discounting. Exactly how unexperienced slices of the future control present behavior - a question of mechanism - is seldom discussed. Instead equations are cast, much as Newton's were; hyperbolae are analyzed while hypotheses are avoided. A similar issue arises in control by the past—how is a "history of reinforcement" embodied? Answers to these questions have been hypostatized; as have assertions that the questions are irrelevant (Baum, 2005, 2012; Rachlin, 1978, 1988; Staddon, 1973; Tonneau, 2013).

Behavioral contrast provides a striking example of strong effects on behavior caused by events situated at other times. It occurs when one context of reinforcement-say a variable interval (VI) schedule in which at random intervals reinforcers follow responses — alternates with 
another context of reinforcement. The typical case is a multiple schedule in which two or more different contexts signaled by discriminative stimuli alternate. If reinforcement frequency is decreased in one schedule, response rates increase in the other, focal, schedule, the one of interest (positive contrast). Conversely, if reinforcement frequency is increased in the alternate (ALT) component, response rates decrease in the focal component (negative contrast). Over 400 articles containing the phrase behavioral contrast have appeared in this journal since Reynolds (1961) introduced the term, identifying many of the variables that affect the phenomenon. It soon became clear that the effect in the focal component depends on the frequency of reinforcement in the alternate component, and not on the behavior that those control (Bloomfield, 1967; Halliday \& Boakes, 1971; Williams, 1980). Inevitably, mathematical models of the effect were developed (Dougan, McSweeney, \& Farmer-Dougan, 1986; Herrnstein, 1970; McLean \& White, 1983; Williams \& Wixted, 1986). These models generally included free constants that were sometimes identified with hypothetical variables, such as alternate reinforcers, but little attention has been paid to measuring stimuli or responses associated with those constructs, or how they might bridge the temporal gap between alternating components. An exception is Hinson and Staddon (1978; 1981), who did report observations of competing behavior that they held to underlie contrast. In this paper their hypothetical mechanism is combined with some of the models of the above authors for a new theory of contrast and its mechanisms.

\section{Reinforcement Inhibition as a Cause of Contrast}

McSweeney (1987) argued that multiple-schedule behavioral contrast occurs because delayed reinforcement suppresses behavior. In particular, reinforcers strengthen behavior that they follow immediately, and suppress behavior that they follow at a delay. Any reinforcers in the subsequent component follow the behavior in the focal component at a delay, and thus they suppress it. If they occur at a higher rate than those in the focal component, they produce negative 
contrast in the focal component; if they occur at a lower rate, the suppression is decreased (from that indigenous to the focal component), and positive contrast is seen. Catania (1973) has also made the case for the inhibitory effects of reinforcement, whereas Donahoe and Palmer (1988) questioned the necessity of the concept of inhibition beyond shorthand for the effects of competition.

McSweeney (1987) arrayed a large variety of evidence that supported suppression by reinforcement as the cause of contrast. She noted that the mechanism of suppression was not resolved, but one candidate was behavioral competition. At that point, over 25 years ago, quantitative predictions from her model were not available. The model proposed here is essentially a vindication of McSweeney's hypothesis, an argument for response competition as the mechanism, and a first pass at quantitative detail.

\section{Behavioral Competition as the Mechanism of Contrast}

Hinson and Staddon (1978) argued that interim (adjunctive) behavior competed with the target response (lever-pressing or key-pecking) and thereby decreased its rate of emission. When the focal component alternated with extinction, the interim behaviors had an opportunity for expression in the extinction component without competing with the target response. This moved them out of the focal component, releasing the target responses from competition. Their hypothesis relies on there being a motivational state driving the competing behavior that, being relieved (or exacerbated) during the alternate component, has the inverse effects on competition in the focal component. It is in that sense a hydraulic model. The motivational hypothesis is consistent with Staddon's conception of interim behaviors voiced elsewhere (e.g., Staddon, 1977b). But there are problems with this hydraulic model, such as the failure to see a change in contrast when the alternate component is switched from VI to signaled VI, the latter leaving ample time for the proposed interim activity to occur, thus reducing the need for it in the focal 
component. This reduction in competing responses should have reduced contrast, but it did not (Williams, 1980; reported in Williams, 1983). There is, however, a different explanation for adjunctive/interim behaviors that forms the basis of the present theory.

Ricardo Pellón and colleagues (Killeen \& Pellón, 2013; López-Crespo, Rodríguez, Pellón, \& Flores, 2004; Pellón \& Pérez-Padilla, 2013) have made a strong case that adjunctive (interim) responses are maintained by reinforcement - that they are operants. They are part of the repertoire of conditioned responses induced by sign learning, and are then enhanced by their regular relation to subsequent reinforcers. They may appear earlier in the behavior stream than target operants such as key pecking because they have shallower, longer delay of reinforcement gradients. Because the gradients are shallower, they are out-competed by the target instrumental response near the time of reinforcement. Because they are longer, they out-compete the target response earlier in the interval. If this is true, then the interim responses that Hinson and Staddon (1978) invoked as the mediator of contrast need not be conceived as induced through a new motivational state. Clearly the most important reinforcer for hungry organisms in an experimental enclosure is food. Interval schedules, most commonly used in studies of contrast, reinforce any sequence of responses that ends in a target response. Killeen (1994) called such off-target responding interbehavior, and crafted a coupling coefficient to predict how much of the reinforcing strength of an incentive went to the measured target response on various schedules, as opposed to such interim responses. On periodic reinforcement schedules those responses may appear as a conspicuous adjunctive behavior, such as the wheel-running with which Hinson and Staddon manipulated the level of contrast for target responses, or as "mediating" (Laties, Weiss, \& Weiss, 1969) or "timing" (Fetterman, Killeen, \& Hall, 1998) responses. On aperiodic schedules, they will be interwoven with the stream of target responses.

In the case of pigeons pecking colored keys, the discriminative stimulus is in their focus whenever a response is made. But other responses - the hypothesized off-target responses - may 
involve movement about the cage, preening, wall-pecking, and so on, and thus be under poorer stimulus control. Furthermore, as grosser movements, many of them may be more memorableintrinsically better marked (Lieberman, Davidson, \& Thomas, 1985) — and thus able to sustain longer delay of reinforcement gradients (Patterson \& Boakes, 2012; Williams, 1991). The competition between target responses and competing responses, and the different speeds with which those behaviors come under the control of discriminative stimuli, is the mechanism for the first type of contrast discussed below. The interaction of target and competing responses with each other and with the conditioned reinforcers or punishers of stimuli signaling component change is the mechanism of the second type of contrast discussed below.

\section{The Types of Contrast}

Behavioral contrast is the change in the rate of responding of an unchanged, focal component of a multiple schedule that occurs as the result of a change in the conditions in an alternate component. The change is typically in the opposite direction of the change in the altered component. Thus, changing a schedule from a multiple variable-interval 3-minute variable interval 3-minute (MULT (VI 3, VI 3)) $)^{\mathrm{i}}$ to a MULT (VI 3,VI 1) will typically cause an increase in response rates in the alternate VI 1 component (no surprise there), and a contrasting decrease in response rates in the focal VI 3 component. This latter is negative contrast. Conversely, a change

to MULT (VI 3, VI 6) will typically cause a decrease in response rates in the changed component, and a contrasting increase in rates in the focal VI 3 component. This is positive behavioral contrast. If changes in the two components are in the same direction, the effect is called induction, not contrast. Two types of contrast are of concern in this paper: Type 1: Variously named transient, local, or transitory contrast. It is argued that these are all manifestations of the same effect, here called initial contrast. It occurs early in training or under conditions of poor 
discriminability. It is greatest at the start of a component, and is most affected by the nature of the prior component. Type 2: Anticipatory contrast, here called terminal contrast. It occurs later in training and under conditions of good discriminability. It is greatest at the end of a component, and is most affected by the nature of the following component. Molar contrast, derived from rates averaged over the whole component, may result from either or both initial and terminal contrast. There are other types of contrast. Dimensional contrast occurs when stimulus control is varied over a dimension, and is manifest by inflections in response rates along that dimension. It may be a manifestation of initial or terminal contrast, depending on the training protocol. Incentive contrast (Flaherty, 1999, also called anticipatory contrast) may be an instance of terminal contrast. In all cases, the proposed mechanism is competition with the target response by other, incidentally reinforced competing behaviors. These latter types will be addressed in subsequent papers.

\section{Initial Contrast}

Initial contrast is also called transient contrast because it is most prominent early in training with exposure to altered rates of reinforcement, is most noticeable at the start of each component (thus local), and may disappear after extended training (and thus transitory). An example is shown in the top panel of Figure 1.

\section{The Competing Responses Hypothesis and the Hysteresis Model}

The thesis of this paper is that the competing interim responses are slower to come under the stimulus control of the different components than are the target response. There are several reasons for such slower acquisition. The target response is typically oriented toward the discriminative stimulus signaling component change, and reinforcement for the target response is typically immediate. The other competing responses are not necessarily oriented toward the 
discriminative stimulus, and reinforcement of them occurs with some delay. Discriminations are acquired more slowly under delayed reinforcement (see, e.g., Mackintosh, 1974, pp. 155 ff.), just as are simple operant and adjunctive responses (see, e.g., Figure 1 of Killeen \& Pellón, 2013).

If competing responses are differentiated more slowly than target responses, they will wax and wane under the control of the reinforcer density, and possibly under control of the target responding as an $\mathrm{S}^{\mathrm{d}}$, and only slowly come under control of the visual or auditory stimuli signaling component change. This is called the hysteresis model. Hysteresis is "the dependence of the output of a system not only on its current input, but also on its history of past inputs. The dependence arises because the history affects the value of an internal state. To predict its future outputs, either its internal state or its history must be known.” (see, e.g., Hysteresis). Different mechanisms that might underlie the hysteresis are discussed in Appendix A, which sends back the following equation, an elaboration of Blough's (1975) model of dimensional contrast:

$$
A_{\mathrm{C}}(t)=e^{-t / \tau} A_{\mathrm{C}, \text { Prior }}+\left(1-e^{-t / \tau}\right) a_{\mathrm{C}} r_{\text {Current }}
$$

where $A_{\mathrm{C}}(t)$ is the strength of competing responses at time $t, A_{\mathrm{C}}$, Prior is their strength just before the change-point, $a_{\mathrm{C}} r_{\text {Current }}$ is its current asymptotic value, and $\tau$ (tau) is the time constant of adjustment. The coefficients $a$ have units of s/reinforcer, and convert rate of reinforcement ( $r$ measured in reinforcers/s) into response strength. Elapsed time $t$ is set to 0 at component transitions. Because the target behavior typically comes under stimulus control quickly (that is, its time constant is negligibly small), an analogous equation for it quickly goes from initial to asymptotic values of $A_{\mathrm{T}}(t)=a_{\mathrm{T}} r_{\text {Current }}$. We do not expect this always to be the case, but reserve the more complicated and parameter-laden case of slower acquisition of target response than competing behavior for a subsequent paper. (Such uphill conditioning is at the heart of the “misbehaviors", "instinctive drift” (Breland \& Breland, 1961; Timberlake, Wahl, \& King, 1982) 
and "contra-preparedness" (Seligman, 1970) of the last century's constraints on conditioning literature (Domjan, 1983; Garcia, McGowan, \& Green, 1972; Shettleworth, 1972).) The history of past reinforcement affects "the value of an internal state" that we identify as the response strength at time $t, A(t)$. Equation 1 is simply how we write down that history as a function of the density of reinforcement $r$, how its nature and quality interact with the organism (a), and how that history fades with the passage of time $f(t / \tau)$. Although Equation 1 derives from a behavioral theory of contrast (Blough, 1975), it may be treated from a more a-theoretical formal stance as the unit response of a first-order control system (see, e.g., McFarland, 1971).

Equation 1a may be rearranged as:

$$
A_{\mathrm{C}}(t)=\left[A_{\mathrm{C}, \text { Prior }}-a_{\mathrm{C}} r_{\text {Current }}\right] e^{-t / \tau}+a_{\mathrm{C}} r_{\text {Current }} .
$$

This form emphasizes that there will be no contrast if the strengths in the prior and current components are the same [the bracketed term equals 0], that the strength of competing responses in the focal component will be decreased if their strength in the prior component was less than that in the current [the bracketed term goes negative], releasing the target response from competition and thus causing positive contrast in the target response. Conversely, if that term is positive, competing responses occur at a higher rate in the prior component, and some of those will slip over into the current focal component, increasing the prevalence of competing responses there, and causing negative contrast in the focal component. Finally, all of these effects will wash out as an exponential function of time, leaving the background competing response strength that is intrinsic to the focal component.

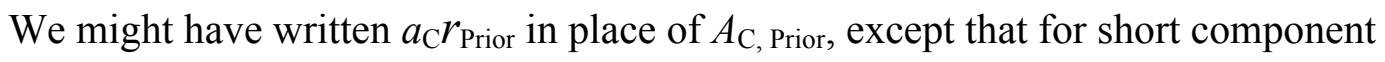
durations it is unlikely that the process would have reached asymptote of $a_{\mathrm{C}} r_{\text {Prior }}$ before components changed anew. Thus the process unfolds from the status quo ante, not from the theoretical extremes. It unfolds toward the theoretical extremes given by $a_{\mathrm{C}} r_{\text {Current }}$ even though it 
may not attain those at short component durations. When components change, then the whole right side of Equation 1 becomes the new $A_{\mathrm{C} \text {, Prior }}$ This is the hysteresis model.

\section{The Response Competition Model}

The rate of target responses in the face of competition from other responses may be derived from the theory of reinforcement schedules sketched in Killeen (1994). From that we have the probability of a target response (the first parenthetical in Equation 2), and the probability that it will not be blocked by a competing [the coupling coefficient, inside the brackets]. Multiply the whole by the maximum response rate $(k)$ to derive the key model, Equation 2 . The term in brackets is a model of coupling: The degree to which the effects of reinforcement are focused on the target response. The steps to Equation 2 are taken in Appendix B. In the absence of competition $\left(A_{\mathrm{C}}=0\right)$, or when it is constant over manipulated variables, Equation 2 reduces to the traditional hyperbolic rate equation (see that appendix). In this paper where stimulus control of the target response is good, the strength attributed to the target response is proportional to the rate of reinforcement in the focal component, $A_{\mathrm{T}}=a_{\mathrm{T}} r_{\text {Current }}$.

$$
B_{T}=k\left(\frac{A_{T}}{1+A_{T}}\right)\left[1-\frac{A_{C}}{1+A_{C}}\right]
$$

The top panel of Figure 1 displays the data from Nevin and Shettleworth (1966) who studied alternating 3-min components of VI 2 min and VI 6 min schedules in a classic multiple schedule arrangement. The bottom panel of Figure 1 shows the imputed changes in $A_{\mathrm{C}}$ as a function of time through the components, for the average $\tau=22 \mathrm{~s}$. This graph of the dynamic change in $A$ closely resembles Figure 4 in Staddon (1982, also reproduced as Figure 9 in Williams, 1983). Although the rendering of them is almost identical, the meaning given to them is 
quite different--for Staddon it concerned satiation and deprivation of the motivation for the competing responses. The curves for the individual subjects were derived using the parameters shown in Table 1. In this analysis the average rate through a bin or component is estimated as the rate at the midpoint of that epoch (see Appendix $\mathrm{C}$ for more detail on curve-fitting). The main difference between subjects in Figure 1 is a larger value of $a_{\mathrm{T}}$ for Pigeon 17 (circles).

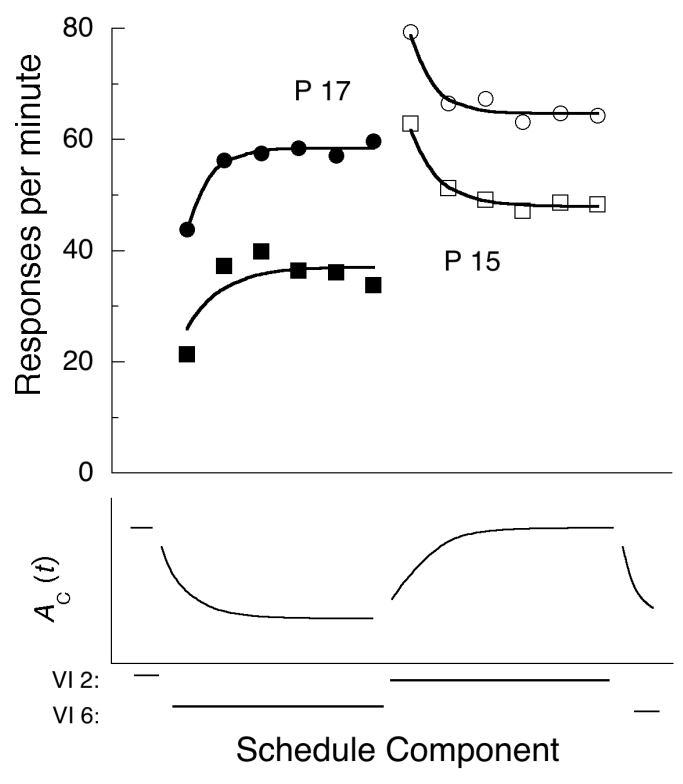

Figure 1. The top panel shows the response rates of two pigeons reported by Nevin and Shettleworth (1966) pecking keys for reinforcement available randomly in time every six min (VI 6; filled symbols) or every two min (VI 2; unfilled symbols). The depression in rates at the onset of the VI 6 component and the elevation of rates at the start of the VI 2 component exemplify behavioral contrast, called local (because most noticeable at the start of the component change) or transient (because it will typically decrease with extended training). The bottom panel shows the hypothetical waxing and waning of the strength of the competing behaviors given by Equation 1 (extrapolated at the left and right ends of the graph). The curves through the data in the top panel are the predicted course of the target response, key-pecking, under immediate stimulus control of 
the key colors, competing against other behavior under lagging control of changes in reinforcement rate, as portrayed in the bottom panel.

Reinforcement is profligate, making contact not only with the target response intended by the experimenter, but also with other responses that may have preceded it or co-occurred with it. The driving force is the scheduled reinforcer, gated efficiently by the signals of component change for the target responses, and laggardly by those signals for the competing responses. If an experimenter intentionally programs reinforcers that are only loosely coupled with the target response, Equations 1 and 2 (and the verbal arguments that motivate them) must predict even more substantial effects. Rachlin (1973) performed that experiment, alternating a VI 2 schedule with a VI 2 schedule having superimposed freely delivered reinforcers at the rate of 4 per minute (a variable time (VT) $15 \mathrm{~s}$ schedule). These free reinforcers, only loosely coupled to the target response, will here act to strengthen the competing responses, with which they may occur closer in time than the target response of key pecking. Figure 2 shows the results of this experiment, along with curves from Equations 1 and 2. Rachlin explained the contrast as following from a Pavlovian "biological principle that a transition from a stimulus signaling a period of low reinforcement value to a stimulus signaling a period of high reinforcement value excites certain [target or competing] responses... . The excited responses are most frequent immediately after the point of transition... . Symmetrically, a transition from high to low reinforcement value inhibits those same responses.” (p. 232). 


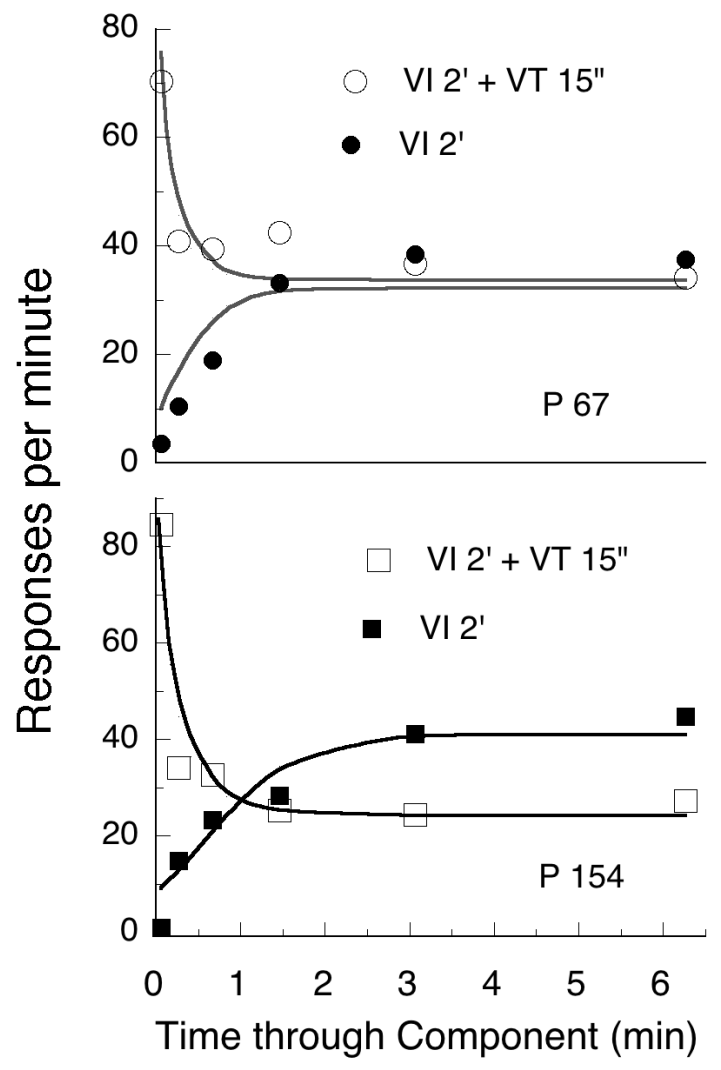

Figure 2. The response rates of the two pigeons reported by Rachlin (1973) pecking keys for food available on a VI 2 schedule (filled symbols) or on a VI 2 schedule with additional noncontingent reinforcers available randomly in time at the rate of 4 per minute (unfilled symbols). Note the very high initial rates on the latter schedule, falling to or below the level of the VI 2 schedule by $90 \mathrm{~s}$ into the component, and the complementary changes on the VI 2 schedule. These patterns are the signatures of local, or initial contrast. Equations 1 and 2 draw the curves using the parameters in Table 1.

Although the larger magnitude of effect in Figure 2 than in Figure 1 could be due to many factors, it is consistent with our argument that the cause of contrast is competition, and when extra 
reinforcement is dispensed in ways that differentially benefit the competing responses, contrast will be enhanced. Whereas these first two figures illustrate the transient local nature of initial contrast, the next will focus on a different aspect of contrast, the effect of component duration.

Table 1:

\begin{tabular}{|c|c|c|c|c|c|c|}
\hline Study: & \multicolumn{2}{|c|}{ Nevin \& Shettleworth } & \multicolumn{2}{c|}{ Rachlin } & \multicolumn{2}{c|}{ Wilton \& Clements } \\
\hline Subject: & 15 & 17 & 67 & 154 & 3 & 24 \\
\hline \multicolumn{7}{|c|}{ Parameter } \\
\hline$k\left(\mathrm{~min}^{-1}\right)$ & 300 & 300 & 300 & 300 & 300 & 300 \\
\hline$a_{\mathrm{T}}(\mathrm{s})$ & 84 & 154 & 23 & 43 & 500 & 500 \\
\hline$a_{\mathrm{C}}(\mathrm{s})$ & 188 & 194 & 61 & 113 & 230 & 162 \\
\hline$\tau(\mathrm{s})$ & 25 & 19 & 14 & 29 & 79 & 86 \\
\hline
\end{tabular}

${ }^{1}$ Parameters were chosen to minimize the RMS deviation between data and model, but with $k$ fixed at a plausible maximum value. See Appendix $C$ for more details.

Wilton and Clements (1971) trained pigeons on a schedule in which a 2 min component of VI 1 was followed by an extinction component (EXT) lasting for different amounts of time from $10 \mathrm{~s}$ to 120 minutes. After EXT a final component lasting 20 min offered reinforcement on a VI 1 schedule. The stimuli for the 3 components were red key, horizontal white line, and vertical white line. The duration of the EXT was changed every day.

The model was applied by letting $A_{\mathrm{C}}$ accrue through the first 2 minutes of the first VI, deplete for the duration of the EXT and re-accrue through the final VI 1 component from which 
these data were taken. Figure 3 gives a blow-up of the process, using the parameters and predictions for the data averaged over both of Wilton and Clements's subjects (circles). The bottom left panel shows how the response strength of competing behavior decreases as a function of time into the EXT component. It has not declined much after $10 \mathrm{~s}$, the first experimental condition. The arrow up from that point shows how it sets the competition level at the start of the final VI component. From that level the strength of competing behavior is quickly recovered to the status quo ante extinction, the same level that is maintained in the following VI. The brief period of recovery gives a transient advantage to the target response, manifest as a small surge in target responding soon back to its original level. That surge is the initial contrast. The average level in the component is shown by the double bar. It may be computed by averaging the predictions of Equations 1 and 2 systematically through the process. That average is called molar contrast, and the dashed line pointing down to the last panel shows that it constitutes the model's prediction for the first experimental point, shown as the circle. When EXT has lasted for $120 \mathrm{~s}$, the strength of competing responses had subsided substantially, as shown by the second arrow up from the first panel. Target responding in the following VI sees much weaker competition, which takes several minutes to return to its status quo. The top right panel shows the larger initial contrast, which elevates the average molar contrast as shown in the last panel. 

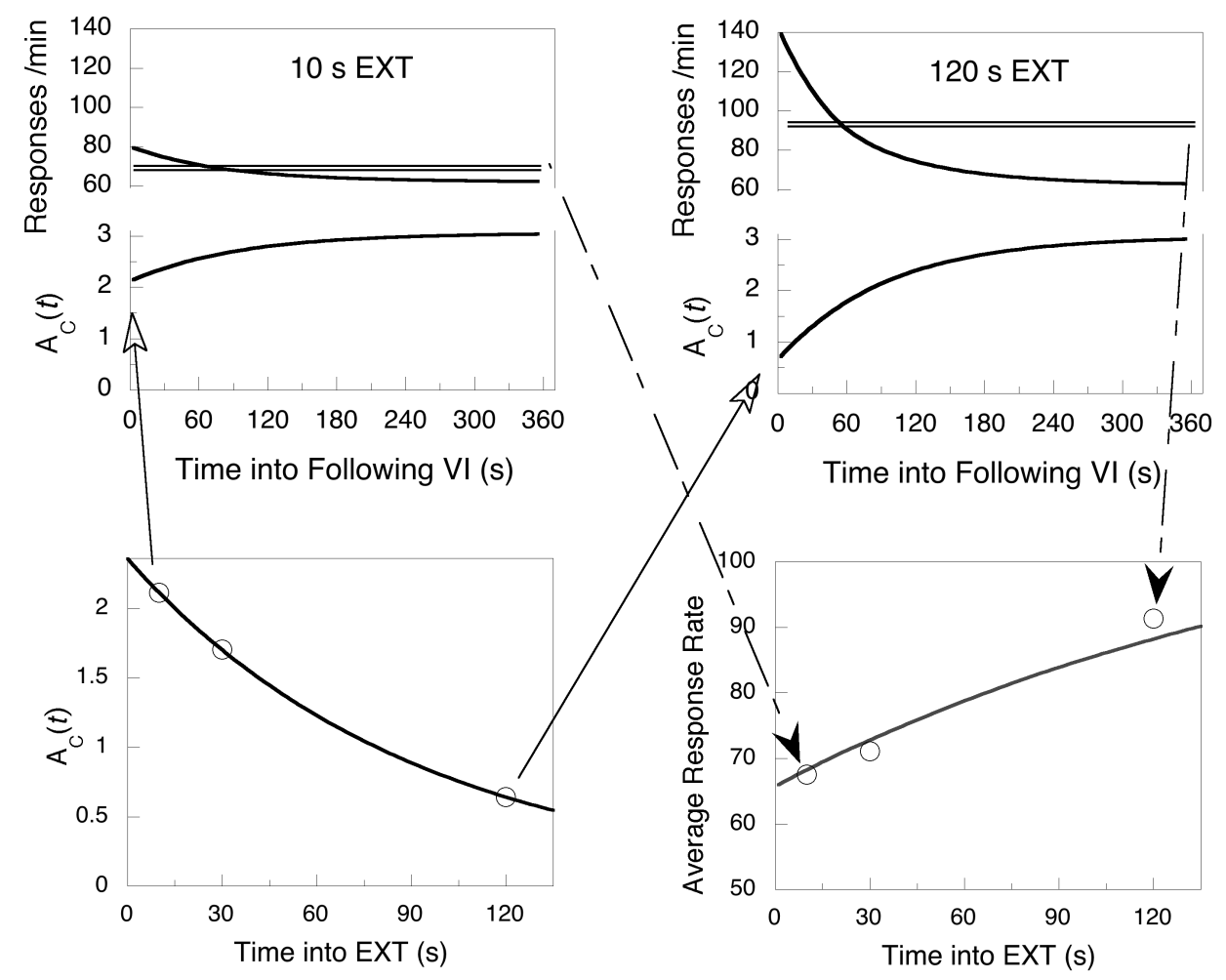

Figure 3. The processes posited to underlie initial contrast, illustrated with the experimental conditions and data of Wilton and Clements (1971), where the strength of competing responses was elevated by a 2 min exposure to VI 1 at the start of each session to $A_{\mathrm{C} \text {,Prior }} \approx a_{\mathrm{C}} r_{\text {Prior }}=2.5$. This corresponds to a probability of about $70 \%$ that the bird would be engaged in a response incompatible with pecking at the start of EXT. It is the intercept of the curve in the bottom left panel. $A_{\mathrm{C}}$ then waned as a function of time into EXT, as shown in that panel. When the final period of VI commenced, the probability of competing responses was set by the level of $A_{\mathrm{C}}(t)$ at that time, as shown by the two arrows issuing from the bottom left panel. Competition recovered from there toward the base rate maintained by the following VI ( $\left.A_{\mathrm{C}}=a_{\mathrm{C}} r_{\mathrm{Current}}\right)$, as shown by the bottom two curves of the top panels. Upon start of the following VI, target responses--under good stimulus control--immediately recovered their base strength; but the slower recovery of competing responses $(\tau \approx 80 \mathrm{~s})$ unleashed target responses, causing the initial positive contrast. The average level of target responses maintained by the first $3 \mathrm{~min}$ of the following schedule is 
shown by the double lines, and constitutes the predictions of the model, dropped into the last panel by the dashed arrow lines.

Figure 4 shows the data obtained for both pigeons over the much larger range of EXT durations studied by these authors. It is a greatly compressed version of the bottom right panel of Figure 3, extending far to the right of those data. The process unfolds over a slower time-course than shown in Figures 1 and 2. This may be due to the more difficult horizontal-vertical discrimination (Thomas et al., 1985) used in this study. In any case, the hysteresis model gives a principled explanation for this component duration effect, in both qualitative and quantitative terms: The longer the EXT period, the weaker the strength of competing behaviors on entering the final VI component.

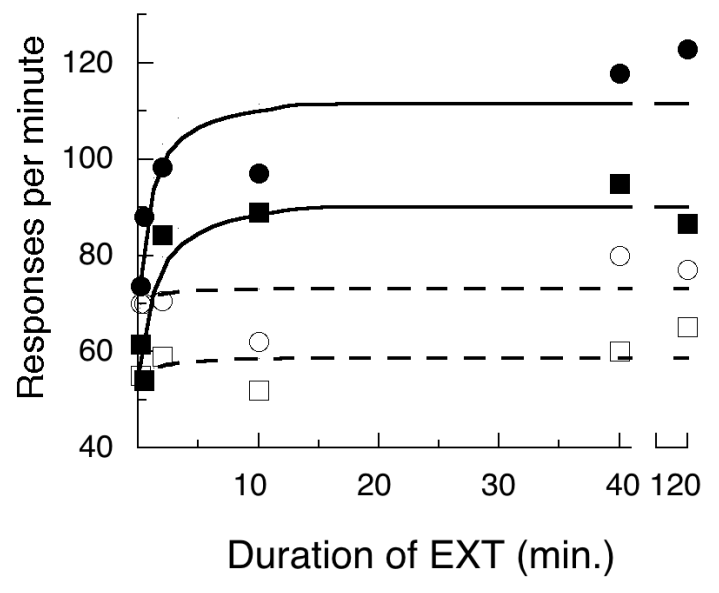

Figure 4. The response rates of two pigeons reported by Wilton and Clements (1971) given a VI 1 schedule followed by a signaled component of no reinforcement (EXT) for the duration noted on the $x$-axis above. The filled symbols come from the first $3 \mathrm{~min}$ of a signaled VI 1 schedule that always followed the EXT component. Increasing the duration of EXT had an increasingly liberating effect on response rates in the following component. The curves are given by the model under the assumption that the strength of competing behavior increases through the first VI 
component, decreases as a function of the duration of the extinction component, and recovers in the final VI component, from which the above data are taken. The filled symbols are an average over the first three minutes of the following VI during which the contrast effect was (presumably) decreasing, as shown in in the top panels of Figure 3. This assumption is reinforced by the open symbols that come from the second $3 \mathrm{~min}$, by which time the contrast effect has largely washed out. The curves are from the hysteresis model with parameters shown in Table 1.

During the second 3 minutes of the final VI the rates showed a very shallow rise, from an average of 63 to 73 responses per min as a function of the duration of EXT. This is because $A_{\mathrm{C}}$ was approaching asymptote by the end of those first three minutes (exponential processes are $95 \%$ complete at $3 \tau ; 99 \%$ complete at $5 \tau$ ), and being back closer to full strength, those competing responses held target responding at the lower rates seen in the open symbols of Figure 4 . The curves in Figure 4 were computed by evaluating Equations 1 and 2 at 15, 45, 75 ... seconds through the following schedule, and averaging their values over the first $3 \mathrm{~min}$, and over the second 3 min. Wilton and Clements also reported data from minutes 6-10 of the following schedule. By then the contrast would have run its course and rates subsided to steady state levels. Those curves were in fact flat, with an average value of 62 responses per min. Using the average values for the two birds from Table 2, $k=300, A_{\mathrm{T}}=500 / 60, A_{\mathrm{C}}=196 / 60$, Equation 2 predicts that the rate will be 62.8 responses per minute.

Component Duration. Figures 3 and 4 provide an excellent picture of one face of the duration effect: The change in the magnitude of contrast as a function of component duration. In those figures it is manifest how lengthening the duration of a preceding component can maximize its effect on the contrast in the terminal link. This is equally the case if it fosters positive contrast, as in those cases, or fosters negative contrast, as would occur when the preceding schedule had a 
richer rate of reinforcement. It is also clear from the top two panels of Figure 3 that because the major amount of contrast occurs in the earliest moments of the focal schedule, lengthening the duration of the focal component will diminish the molar contrast averaged over that extent. Thus there are actually two duration effects: The enhancement of initial contrast as the duration of the preceding component lengthens, and the decrease in average contrast as the duration of the focal component increases. Conversely, if the duration of the following target schedule in the top right panel of Figure 3 were restricted to $30 \mathrm{~s}$, the average response rate during it would have increased from 91 to about 120 responses per minute.

Duration effects have been often noted (e.g., McSweeney, 1982), typically with the durations of both components simultaneously varied. Figures $1-3$ show that the major effect of hysteresis occurs in the earliest part of the focal component, and so the average effect will decrease as that component lengthens. Even while shortening component durations selects from the most 'contrasty' part of the focal component, shortening the ALT component decreases that effect by not letting competing responses come near their asymptotic values--be those low, as the case for low reinforcement rates in the ALT and the ensuing positive contrast (see Figures 3 and 4), or high, as the case for high rates of reinforcement in the ALT component and the ensuing negative contrast. For nonlinear phenomena such as these it is difficult to intuit which effect should dominate when both component lengths are varied together-it depends on the particulars and the parameter values. Therefore the hysteresis model was applied to two additional of the early studies of the duration effect, and to a later one.

In the first systematic study of component duration in multiple schedules, Shimp and Wheatley (1971) exposed 3 pigeons to a variety of VI schedules and durations, enforcing a 1-s 
change-over delay (COD) before possible reinforcement in the alternate component. The majority of conditions involved an approximate 4:1 ratio of obtained reinforcement rates in the components, with one component always VI 1 and the other varying from VI 3.3 to VI 5. Average relative response rates of three birds are are taken from their Figure 1 and displayed as diamonds in Figure 5. It is clear that at short component durations response proportions approached the 4:1 ratio of reinforcement rates, and they decreased with increases in component duration. In a similar experiment published the next year, Todarov (1972) studied 3 pigeons on a range of component durations, utilizing VI $30 \mathrm{~s}$ and VI $90 \mathrm{~s}$ schedules with no COD in force. The circles in Figure 5 show that, like Shimp and Wheatley, Todorov found a systematic decrease in response proportions as duration increased. At short durations his data did not quite attain the matching proportion of 0.75 , and showed a small downturn at 5 -s components, due perhaps to the absence of a COD.

Charman and Davison (1982) failed in their first 3 experimental conditions to find a duration effect. Finally in their last experiment, they conducted a relatively close replication of the Todarov procedure, in particular keeping the rich (VI $30 \mathrm{~s}$ ) and lean (VI $90 \mathrm{~s}$ ) components associated with the same key colors while varying component duration. Figure 5 shows that they were finally successful in finding the effect, down to a small downturn at the very shortest duration (they did not report using a COD). 
Killeen Page 22

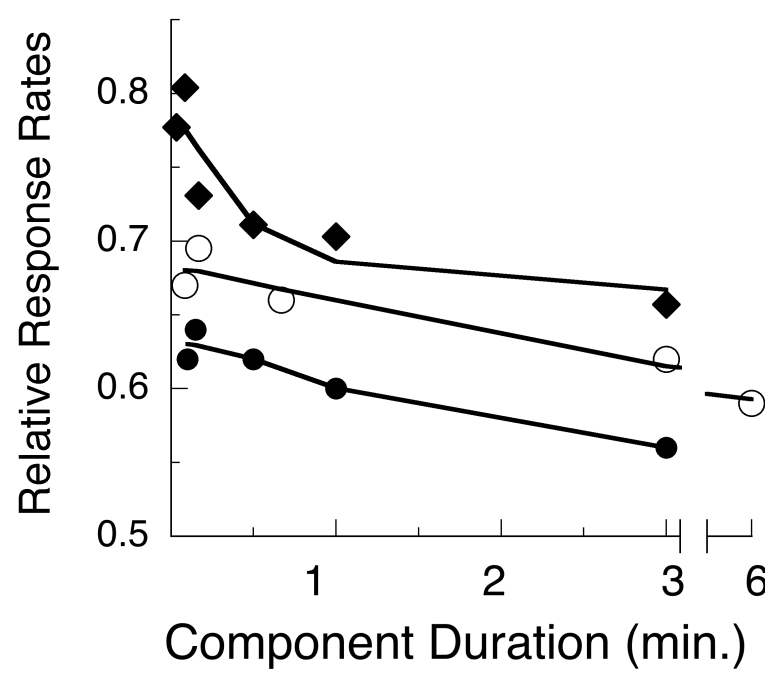

Figure 5. The duration effect as reported by Shimp and Wheatley (1971, diamonds) by Todorov (1972, circles), and by Charman and Davison (1982, discs). The curves are drawn by hysteresis model using the parameters in Table 2.

We may apply the model to these data. Because the changing component duration would make the midpoint analysis used in the first three figures sysematically biased, Equation 1 was integrated to provide the average response strength through the interval (Equation $\mathrm{C} 1$ ). At short durations there is fairly substantial carry-over of competing responses, enhancing or diminishing rates as a function of the value of the preceeding component. This effect wanes as component durations increase. The curves are derived by taking the relative values of $B_{\mathrm{T}}$ for each of the components from Equation 2. Figure 5 shows the account given by the model, with the values of activation for competing and target responses $\left(a_{\mathrm{C}}\right.$, and $\left.a_{\mathrm{T}}\right)$ and time constant tau $(\tau)$ given in Table 2. The scale factor $k$ cancels out of this relative measure. The curve for Shimp and Wheatley (1971) lies above the others because they used a more extreme ratio of reinforcement rates in the components. 
Table 2

\begin{tabular}{|c|c|c|c|c|c|}
\hline Study: & $\begin{array}{c}\text { Shimp \& } \\
\text { Wheatley }\end{array}$ & Todorov & $\begin{array}{c}\text { Charman } \\
\text { \& Davison }\end{array}$ & Williams & Avg $^{1}$. \\
\hline$a_{\mathrm{T}}(\mathrm{s})$ & 10 & 24 & 56 & 160 & 72 \\
\hline$a_{\mathrm{C}}(\mathrm{s})$ & 97 & 40 & 30 & 66 & 79 \\
\hline$\tau(\mathrm{s})$ & 6 & 30 & 24 & 19 & 23 \\
\hline
\end{tabular}

${ }^{1}$ Weighted (by number of subjects) trimmed (20\%) mean of all parameters in Tables 1 and 2.

The hysteresis model suggests why Charman and Davison's (1982) first three attempts failed. Despite a wide variety of procedures, one thing in common was their reassignment of keycolors from rich to lean schedules between each condition change. This continual switching may have kept the competing behaviors from ever differentiating through the course of the various components. One simple way of simulating that hypothesis is to set $\tau$ at an arbitrarily large value. This extends the competing responses uniformly both within and between components, and has the effect of moving proportions to a uniform and insensitive value. For Charman and Davison's conditions and the parameters in Table 2, this levels all relative rates to 0.63 . If competing responses were quickly brought to equilibrium, simulated by setting $\tau$ to a value of 0.1 , proportions would again be flattened, this time to a lower value of sensitivity 0.53 . Another way to bring competing responses closer to equilibrium is by letting time lapse after the offset of one component before the onset of the next. In their Experiment 3, Charman and Davison found substantially reduced sensitivities when they inserted blackouts between components.

By shortening the duration of both components together, both the weakening (or enhancement) of competing behavior in the ALT component and the contrasting effects in the 
focal component are being truncated or extended together (Williams, 1989). The nonlinear tradeoffs, along with the interaction between the value of $\tau$ and the component duration, blinker intuitions about response rates, so let us turn to the model for predictions. The response rates predicted for a VI 3 schedule alternating with either EXT or VI 1 at various component durations are shown in Figure 6, using the parameters from the last column of Table 2 (dashed lines). They predict a convergence of response rates at longer component durations. Also shown are data from Williams (1980), who conducted the experiment. Shortening durations increases contrast, as seen in Figure 6, and will pari passu increase sensitivity (approach to matching) in ratios of the rates. It is notable that the components of concurrent schedules are typically of very short duration, and thus approach matching.

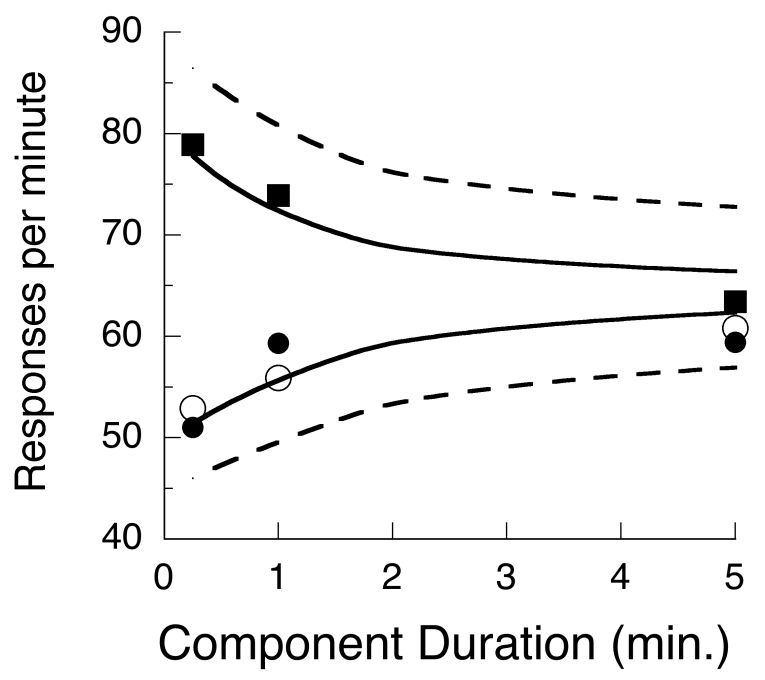

Figure 6. The dashed lines show the predictions of the model using the parameters in the last column of Table 2 and $k=300$, for a VI 3 schedule alternating with another (EXT, top curve, VI 1 and signaled VI 1, bottom curve). The symbols represent data reported by Williams (1980). Squares are for when the alternate was extinction, circles when it was a standard VI 1 min 
schedule, and disks when it was a signalled VI 1 schedule. The continuous curves are the fit of the model with parameters tuned to those data (see Table 2).

Summarizing these contrary effects: If the focal component is held constant and the ALT component duration is increased, contrast should increase, as the competitive responses will have more time to approach their max (or min), the effect seen in Figures 3 and 4. If the ALT component is held constant and the focal component duration is increased, contrast should decrease, because most of the contrast occurs in the first $\tau \mathrm{s}$ of the component. Increasing focal component duration therefore washes out the average effect. The data support these predictions (Williams, 1989). If both components are varied together, then, for representative parameters (dashed lines of Figure 6) contrast will decrease with increases in the component durations. The magnitude of these effects will covary with the value of $\tau$. To the extent that $\tau$ is shorter than the shortest component duration, average effects of manipulating that duration will be small.

In noting the effects of varying the duration of the EXT component on positive contrast and its eventual disappearance, Hinson and Staddon suggested that "local contrast effects represent a temporary disequilibrium between competing activities and the instrumental response" (1981, p. 275). That is the thesis of this paper, with the caveat that the disequilibrium is due to the differential rates of bringing instrumental and competing responses under stimulus control, driven by the same reinforcers, not "other" reinforcers, and not induced motivational states.

This last point is brought home by the round data points in Figure 6. It was rate of reinforcement in the ALT component (here, VI 1), not rate of responding, that matter for contrast and the duration effect. The presence of vigorous pecking (filled circles) or absence of it (open circles) had no effect on contrast or the duration effect. Although a similar dependence on 
reinforcement rates, not response rates, had been shown before numerous times starting with Reynolds (1961), Williams's experiment challenges Hinson and Staddon's (1981) account of a squeezing of competing adjunctive responses out of the richer ALT component (by target responding) into the focal component, thus causing negative contrast. The signaled VI schedule gave ample time for adjunctive responses - no squeezing - , but that made no difference in the amount of contrast. The present account, rather than be discomfited by Williams's results, is encouraged by them, as it predicts the rate of reinforcement in the ALT schedule to be the engine driving the response strength of competing behavior, whether or not that engine is coupled to measured responses in the ALT component.

Non-standard target responses will sometimes give non-standard results. Bernheim and D. R. Williams (1967) demonstrated transient initial positive and negative contrast, a duration effect, and possibly terminal contrast using wheel-running as the target response. McSweeney (1982) studied the duration effect in pigeons with both key-pecking and treadle-pressing responses. She found the standard duration effect for key pecking, but a reversed effect with treadle pressing. She and other investigators have found a variety of effects using treadle pressing as the target response, including some difficulty in demonstrating contrast (Dougan, et al., 1986; Hemmes, 1973; McSweeney, 1983; McSweeney, Dougan, Higa, \& Farmer, 1986). Rather than delve into this rich and confusing literature, it should be noted that the specific activation $a_{\mathrm{T}}$ for treadle pressing as a target response is apt to be less than that for key pecking, and its time constant likely to be greater. That is because a competing response such as pecking the wall near the stimulus may be under better control of the component stimuli than is a treadle-pressing target response. Under those conditions, baseline rates for treadle pressing can drift, and that drift may bring it into greater or less contact with reinforcement (Killeen \& Pellón, 2013), and thereby cause substantial order-effects (e.g., King \& McSweeney, 1987), and a reversed duration effect. 


\section{Terminal Contrast}

The lag in component stimuli acquiring discriminative control over competing responses may be due to many factors in addition to the difficulty of the discrimination. Reinforcement of competing behavior typically occurs at a delay, whereas that for the target response occurs immediately. Delays impede learning for adjunctive responses, just as they do for instrumental responses (Killeen \& Pellón, 2013). All of these effects can make initial contrast endure for many sessions before the competing responses come under stimulus control and initial contrast disappears. Difficult discriminations may never be learned, and then contrast will be maintained. The continuum of easy-to difficult discriminative stimuli, and the differential contrast that they sustain, may be one of the causes of dimensional contrast. But if the competing behavior does come under stimulus control, then as initial contrast fades a new type of contrast may appearterminal contrast, described now.

Buck and associates (Buck, Rothstein, \& Williams, 1975) provided early data tracing the course of the following schedule effect - here called terminal contrast. These investigators alternated VI and EXT schedules for four pigeons in a multiple arrangement with $90 \mathrm{~s}$ components. They found that positive contrast occurred toward the end of the component, and increased with training (not decreased, as does initial contrast). After 26 sessions the subjects were re-exposed to a MULT (VI 2, VI 2) baseline, and then the whole procedure was replicated. Figure 7 shows the median response rates through the VI schedule averaged over original and replication. It is positive contrast, as rates are higher in the VI when it is alternated with extinction than with a comparable VI; but it is unlike all of the studies analyzed thus far, as the rates start low and increase through the component, rather than start high and then decrease. The authors noted that: "In a given procedure, either or both types of interaction [initial and terminal] may 
occur; neither [by itself] provides a complete account of behavioral contrast" p. 291. (The pattern in Figure 7 might also be interpreted as induction of the depressed EXT rates into the VI component. This is unlikely given the clarity of the stimuli and length of training, given Williams's follow up experiments, and in light of the analysis shown in Figure 8.)

In numerous subsequent studies (e.g., 1980; 1981, 1983; for overview, see 2002), Williams independently varied the preceding and following schedules, and demonstrated the reliability of control by the following schedule independently from the control by the preceding schedule, and reviewed the effects of training, stimulus discriminability and within-component changes in rates on the following schedule effect.

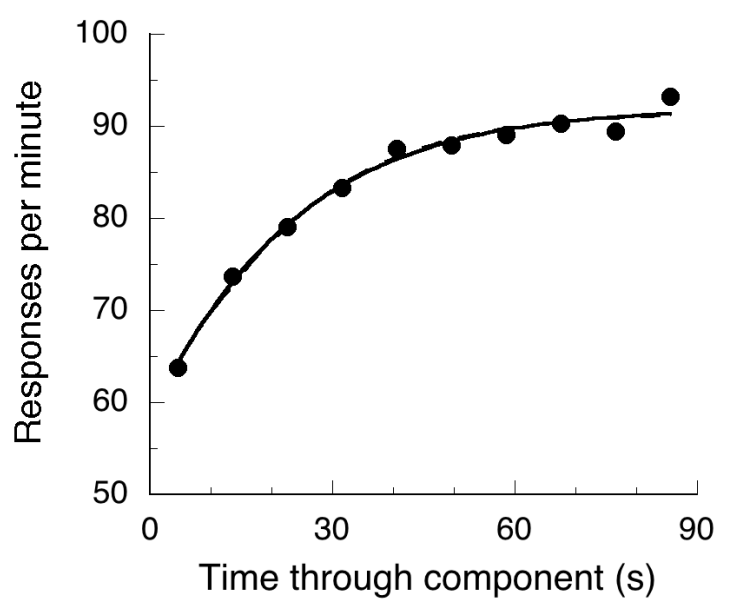

Figure 7. Median response rates of four pigeons (Buck, et al., 1975) demonstrating terminal contrast in $90 \mathrm{~s}$ components of VI 2 alternating with EXT.

Williams (2002) noted the "paradox" of anticipatory contrast in that Pavlovian signals of forthcoming improved conditions are expected to be excitatory, signals of forthcoming impoverished conditions to be inhibitory. Terminal contrast works just the other way around, 
discomfiting Pavlovian accounts. In our view it does so because the modus operandi of terminal contrast is on other responses more strongly than target responses, and by exciting or inhibiting them, has contrary effects on target responses.

\section{The Differential Consequation Hypothesis}

It is our hypothesis that the cause of terminal contrast is the sensitivity of interim and adjunctive responses to the stimulus signaling the following component. That stimulus can have strong conditioning (reinforcing or punishing) effects on the responses that preceded it (Royalty, Williams, \& Fantino, 1987). Those effects are more likely to impact the competing behavior, as component change occurs independently of the brief instrumental response, and is more likely to be contiguous with non-target responses. When stimulus control of competing behavior is poor, then initial contrast may occur, and will decrease as the discriminative control of the components is established. With such extended training the component stimuli may assume conditioned reinforcing or punishing strength along with their discriminative functions. These predictions are sustained:

with more similar stimuli, the maximum degree of interaction occurred at the beginning of the components and then decreased [our initial contrast]; with less similar stimuli, the degree of interaction increased throughout the components and was at its maximum near their end [our terminal contrast]. (Williams, 1988, p. 206).

By comparing the results of following schedules of either VI and EXT that were distinctively signaled or not (i.e., they were mixed schedules with respect to one another, but distinctive from what preceded and followed them), Williams (1979, p. 392) was able to conclude 
that "conditioned reinforcement plays a major role in such suppression" of target responses in the case of negative contrast. We infer that that is due to the reinforcement of competing responses. Equally, we would add, that conditioned punishment (when a signal of EXT or lower reinforcement rate follows) plays a major role in suppression of competing responses, and thus liberation of instrumental responses toward the end of that component-terminal positive contrast.

Both instrumental (Cowie, Elliffe, \& Davison, 2013; Williams \& Royalty, 1990) and competing responses come to be organized with respect to time through the component. As imminence of reinforcement in the alternate schedule increases, the distribution of competing interim responses in the target component changes systematically with it (Haight \& Killeen, 1991), as does the amount of contrast shown by the instrumental response (Williams, 1976). The following section provides a candidate model for these effects.

\section{The Competing Traces Model of Terminal Contrast}

How does a reinforcer connect to a prior response? Some vestige of it, in action or in memory, must be affected by the reinforcer. These hypothetical vestiges are called traces, and are pictured in Figure 8. Killeen and Pellón (2013) argued that adjunctive responses may be more memorable than target responses such as a key-peck, and persist in memory longer because of that. They developed a logistic model of trace competition to explain some of the variance in the presence and temporal location of adjunctive responding. In the present situation it is not primary reinforcement, but rather the conditioned reinforcement (or punishment) of competing responses that--we propose--causes terminal contrast. The arguments are similar-the effects of reinforcement on responses with different sensitivities, which compete with each other for expression. Killeen and Pellón's work focused on the competing adjunctive responses, whereas this paper focuses on the effects of those response on the measured target response. 


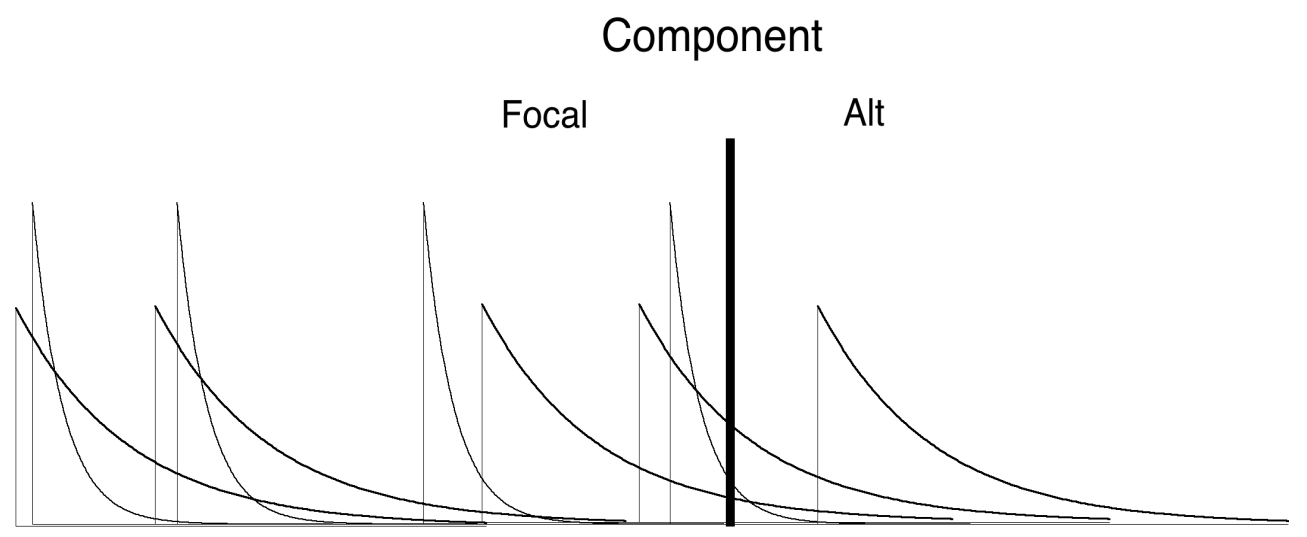

Figure 8. Target responses such as key pecking and their traces are depicted by the taller curves. Interim responses and their traces are depicted by the shorter curves. Stimuli signaling component change from Focal to ALT may punish or reinforce responses in memory at that time depending on the reinforcement differential that they signal. In addition, when components change from Focal to Alt, any of the responses with tails to the right of the vertical bar are available for primary reinforcement, or for extinction if the ALT component is EXT.

We posit a modification of Equation 1 to accommodate the support for adjunctive behaviors intrinsic in the focal component, and the suppression or enhancement of them by the stimuli associated with component change. The support is proportional to the rate of reinforcement in the focal component. The change in rate going into the following component adds additional conditioned reinforcement or punishment:

$$
A_{\mathrm{C}}=a_{\mathrm{C}}\left(r_{\text {Current }}+w_{T}\left[r_{\text {Following }}-r_{\text {Current }}\right] f(t)\right)
$$


The strength of competing behaviors $\left(A_{\mathrm{C}}\right)$ is proportional $\left(a_{\mathrm{C}}\right)$ to the rate of reinforcement in the focal component ( $\left.r_{\text {Current }}\right)$ plus the conditioned reinforcement or punishment due to the change signaled by the following component stimuli, $\Delta_{\mathrm{T}}=w_{\mathrm{T}}\left[r_{\text {Following }}-r_{\text {Current }}\right]$. Note that if the following component has a lower rate of reinforcement than the current focal component, delta $(\Delta)$ is negative, indicating a punishing effect of component change on competing behavior. If the following schedule stimuli signal an increased rate of reinforcement, delta is positive and adds further support for competing behavior in the focal component. If there is no change in reinforcement rate, delta is zero and there is no conditioned effect; there is instead the base-rate support $a_{\mathrm{C}} r_{\text {Current, }}$ unmodulated by time through component. The parameter $w_{\mathrm{T}}$ indicates the importance of the following schedule effect. Early in training it will equal zero, and will increase with training.

On components with fixed durations the strength of the conditioned effects will increase with proximity to the end of the component, near the locus of the component change, as some function of time, $f(t)$. Ensembles of interim responses arise on schedules (see, e.g., Haight \& Killeen, 1991; Innis, Simmelhag-Grant, \& Staddon, 1983; Pear, 1985; Reid, Bachá, \& Morán, 1993; Roper, 1978), any of which can compete with the target response. A number of simple timing models were assayed for $f(t)$ (e.g., Rayleigh (Reid \& Allen, 1998), Weibull (Killeen, Hall, Reilly, \& Kettle, 2002), and normal (Gibbon, 1977)). The cumulative exponential distribution, $f(t)$ $=1-e^{-t / \tau}$, was the best simple model. It is the simplest instance of the extreme value distribution, which gives the time of onset of the first of any one of a set of random processes; and of the first stage of a set of gamma-distributed processes, which has also been used to capture the temporal distributions of interim activities (Killeen, 1975; Osborne \& Killeen, 1977). With that instantiation of $f(t)$, placing $A_{\mathrm{C}}$ in the right-hand side of Equation 2 provides the model of terminal contrast. Together they draw the curve through the data in Figure 8 using parameters of $k=240$ 
$\min ^{-1} ; \tau=18 \mathrm{~s}$, and specific activations $a_{T}=74 \mathrm{~s}$ and $a_{C}=66 \mathrm{~s}$. Because the following schedule was EXT in that experiment, $r_{\text {Following }}=0$. The weight of terminal contrast $w_{\mathrm{T}}$ was set to 1 , as the data were collected after an extended regimen of training.

One way to test the conditioned consequation hypothesis is to ask whether the putative reinforcing strength of the component stimuli changes appropriately under manipulation of variables known to affect conditioned reinforcement. One powerful manipulation known to affect conditioned reinforcement strength is delay of reinforcement, (e.g., Royalty, et al., 1987). By making the component change into the following schedule signal fixed delays to food, it should be possible to change the rate of competing responses, and thus inversely the target response rate. If it signaled a short delay, the change would constitute positive conditioned reinforcement, enhance competing responses, and generate negative contrast. If it signaled a long delay, it would signal a decrease in the local reinforcement rate, punish competing behavior, and thus generate positive contrast.

Williams (1976) performed the experiment with 6 pigeons working under a MULT (VI 90 s, FI $x$ ) schedule. The components were of $90 \mathrm{~s}$ duration, and the values for the FI were $5 \mathrm{~s}, 45 \mathrm{~s}$, and $80 \mathrm{~s}$, experienced in a counter-balanced order. Williams reported the data for each bird at each fifth of the VI schedule. I have averaged the data and present them in Figure 9. Note that with reinforcement immanent in the ALT component (viz. FI 5 s), rates in the focal VI schedule showed strong negative contrast (filled circles), as predicted. In the remaining conditions, with reinforcement in the ALT remote there was no hint of negative contrast, and even a suspicion of positive contrast. Equations 2 and 4 drew the curves with parameters given in the figure caption.

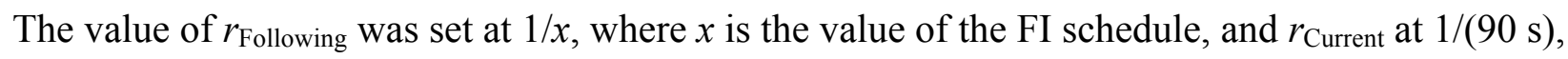
the rate of reinforcement on the VI schedule. The weight of terminal contrast $w_{\mathrm{T}}$ was set to 1 . 


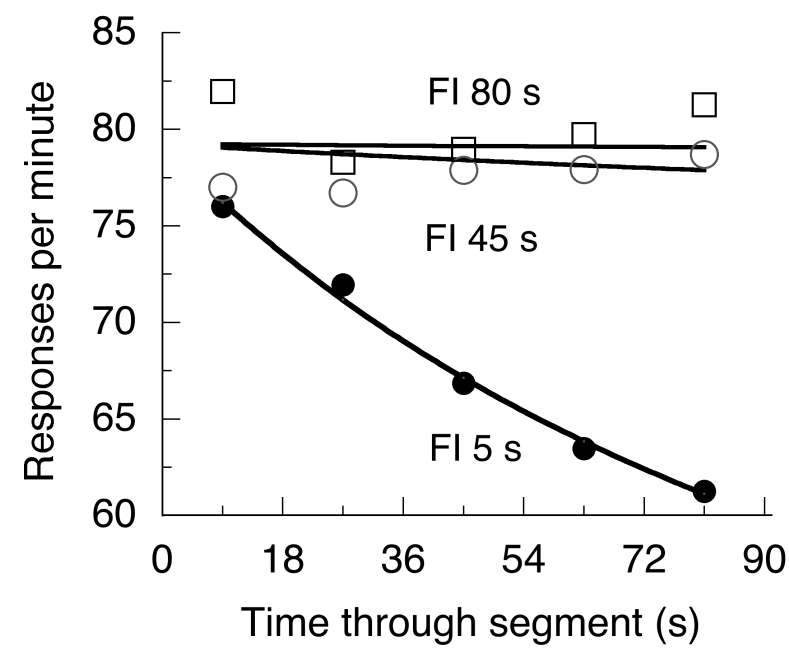

Figure 9. Response rate in the unchanged VI $90 \mathrm{~s}$ component in an experiment by Williams (1976), who varied the location of reinforcement in the ALT component by scheduling it on Fixed Interval (FI) schedules with periods of 5, 45, or $80 \mathrm{~s}$. The curves are from the response traces model of terminal contrast, with parameters of $k=240 / \min a_{\mathrm{T}}=48 \mathrm{~s}, a_{\mathrm{C}}=5 \mathrm{~s}$, and $\tau=180 \mathrm{~s}$.

\section{Problems with the Competing Traces Model}

There are apparent problems with the idea that the signal for the following schedule can punish behavior. Williams and Dunn (1991) found a punishing effect on choice when pecking responses on concurrent chain schedules led to a probabilistic time-out, but the effect was small. More pertinently, in the same study that Williams (1980) analyzed the duration effect shown in Figure 6 above, he ran a condition of signaled reinforcement in the alternative component, and found data (the open circles in Figure 6) virtually identical to that from the same, but unsignalled, VI (the disks in Figure 6). But the component stimulus change was effectively signaled EXT (until the $\mathrm{S}^{+}$occurred just before reinforcement). Why should the data not have looked more like the squares, associated with EXT? Frankly I do not know. My hypothesis is that, with a VI 
schedule, some instances of reinforcement will occur soon after component transition, and they will do more than their share in strengthening alternate responses in the focal component (Killeen, 1968). Furthermore, the signaled extinction condition is not very different from the 3-link chain schedule studied by Bell and Williams (2013) in which the middle link, when predictive of a delayed reinforcer at the end of the third link, was demonstrated to have "potent conditioned reinforcement properties" (p. 179). Thus, although the pigeons learned that they need not respond during the EXT/delay stimulus, that stimulus signaled the same distribution of delays as did the VI stimulus, and its onset may have been equally reinforcing or punishing as that stimulus. According to the present theory it is the signaling of the following schedule reinforcement distribution that gives potency to the component stimuli, not the behaviors that they govern. That potency may have been equal in these conditions. If this hypothesis is correct, then in schedules with fixed delays to reinforcers there should be a regular transition from negative to positive terminal contrast with increases in that delay (even though all signal a period of EXT until that interval elapses). As reflected in Figure 9, Williams (1976) found the predicted negative contrast and its attenuation in five of six pigeons he studied when the FI in the following component was lengthened, and found some evidence for positive contrast at the longer FIs in four of those birds. These latter results support the competing traces model.

In a more relevant experiment Williams (1988) compared the following-schedule effect when transitions between the focal component and the following component were peckcontingent, and when they were not. He achieved appreciable terminal contrast but found absolutely no differences in the amount of contrast between dependent-transition conditions and non-contingent conditions. The reinforcement or punishment of competing behavior by schedule transition is a key aspect of the consequation hypothesis. What does this lack of effect for transition contingencies on the target response do to that hypothesis? One could suppose that his 
contrast effect was primarily initial contrast—-but his experimental conditions ruled this out. One could suppose that the schedule transitions were not conditioned reinforcers or punishers-but Williams's own work makes this unlikely (Bell \& Williams, 2013; Williams, 1994). In any case, if the schedule transitions were not functional conditioned reinforcers or punishers, that alone would undermine the machinery necessary for the present theory. Our hypothesis is that because these subjects had been in similar experiments for years, pecking had come under fairly strong control of consequation by grain reinforcers, and was not sensitive to the contingent change in components. Highly conditioned behavior can become habitual, less sensitive to consequences (Dickinson \& Balleine, 2002). If it were sensitive, we would expect to see some enhancement or diminution in pecking due to contingent conditioned reinforcement or punishment. There was none. Had Williams been able to identify the key competing behaviors and consequate them, then the theory would be tested.

Nevin, Smith and Roberts (1987) found contrast effects when pigeons transitioned from a VI 180 schedule to EXT, but the degree of contrast was not affected by whether the transition was peck-contingent or not. Transition to a higher rate of reinforcement in the ALT component generated negative contrast (with respect to the above conditions), but rates in the peckcontingent change were higher than those in the non-contingent change. From this we may infer that signals of decreased rate of reinforcement are less effective punishers of pecking than signals of increased rates of reinforcement are reinforcers (also shown in Killeen, Sanabria, \& Dolgov, 2009). If this is also the case for competing responses - that reinforcement has more impact on behavior than does non-reinforcement - it would suggest that positive terminal contrast would be more difficult to demonstrate (apart from ceiling effects) than negative terminal contrast. 


\section{A General Model of Contrast}

Equation 2 was formulated as the product of the probabilities of engaging in the target response $\mathrm{B}_{\mathrm{T}}$ and not engaging in competing responses $\mathrm{B}_{\mathrm{C}}$, Initial that are carried over from (or extinguished in) the prior component. Equation 4 performed a similar service for terminal contrast. We may unify those models by recognizing that competing behavior in the focal component has the possibility of being modulated both by carry-over effects from the prior component and by conditioned effects from the following component. Then Equations 1 and 4 become Equation 6:

$$
A_{\mathrm{C}}=a_{\mathrm{C}}\left(\Delta_{\text {Initial }} e^{-t / \tau_{\mathrm{I}}}+r_{\text {Current }}+\Delta_{\text {Terminal }}\left(1-e^{-t / \tau_{\mathrm{T}}}\right)\right)
$$

where

$$
\Delta_{\text {Initial }}=w_{\text {Initial }}\left[r_{\text {Prior }}-r_{\text {Current }}\right]
$$

and

$$
\Delta_{\text {Terminal }}=w_{\text {Terminal }}\left[r_{\text {Following }}-r_{\text {Current }}\right] .
$$

Upon evaluation, Equation 6 is inserted into Equation 2.

It is the thesis of the competition hypothesis that competing responses from a prior richer component spill over to cause initial negative contrast; and the dearth of them when the prior component is EXT continues into the focal component to cause initial positive contrast. They will decrease through the component (the first exponential term in Equation 6) as the animal comes to its senses. These effects are represented in Equation 6P, and weighted by $w_{\mathrm{I}}$, which will at first increase with training as the $\mathrm{B}_{\mathrm{C}}$ become conditioned, and then decrease with training as they 
come under the control of the component stimuli (if that happens) in a manner figured by the circles in the top panel of Figure 10.

The middle term in Equation 6 shows that there is always some level of competing responses maintained by the reinforcement schedule. This might also receive a weight, as such competition will be more common in interval schedules than ratio schedules, but that has not been necessary for the present analysis. Equation $6 \mathrm{~F}$ represents the reinforcing or punishing effects of the following schedule as the product of the difference it signals from the current schedule with its weight. We expect that weight to increase with training, as shown by the disks in the top panel of Figure 10. In Equation 6 this term is also weighted by its proximity to the end of the interval, the point where its force is concentrated. They are combined with a simpler equation for the target response strength (here assumed to be under strong stimulus control: $A_{\mathrm{T}}=a_{\mathrm{T}} r_{\text {Current }}$ ) in the basic rate equation, 2 .

The same Buck, Rothstein and Williams (1975), who provided the data in Figure 7 also reported the data from one pigeon throughout all stages of training. Those are shown in the bottom panel of Figure 10, with the curves from Equation 6. The values of the weights $w$ on interim and terminal contrast were let free to vary across blocks to minimize rms error, and took the values shown in the top panel of Figure 13. The probability of a target response was held constant at 0.27 throughout by $a_{\mathrm{T}}=45 \mathrm{~s}$. 

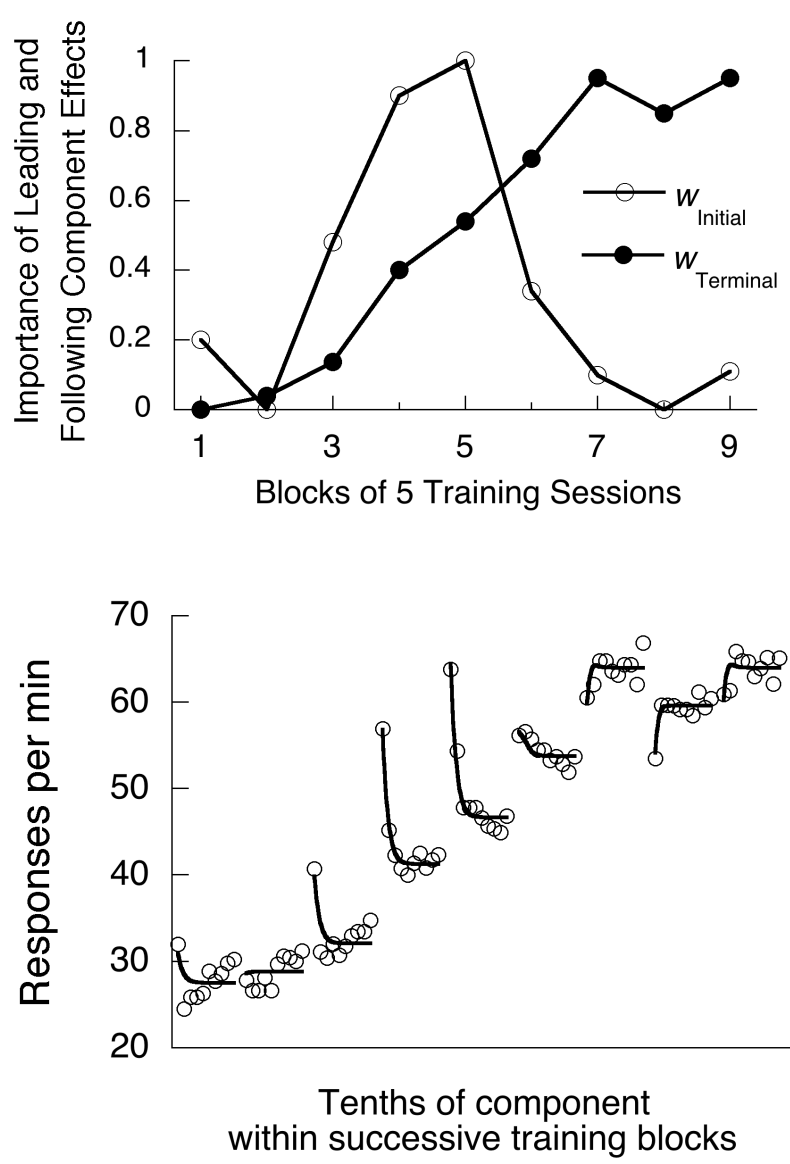

Figure 10. The bottom panel shows one pigeon's response rates (from Buck, Rothstein and Williams, 1975) in 5 session blocks. Within each block rates are shown for successive tenths of the 90 s components of a VI 2 that alternated with EXT. The curves are given by Equations 2 and 6 , with $k=240 \mathrm{~min}^{-1}$, and $a_{\mathrm{T}}=45 \mathrm{~s}$. The time constants for initial and terminal contrast were $7 \mathrm{~s}$ and $2.5 \mathrm{~s}$. The top panel traces the evolution of initial contrast (circles) and terminal contrast (disks).

When terminal contrast has not developed, the competing responses susceptible to it, $\mathrm{B}_{\mathrm{C}}$, continue toward strength $a_{\mathrm{C}} r_{\text {Current }}$ without further modulation by time through component. When 
components are long enough so that $A_{\text {Prior }} \approx a_{\mathrm{C}} r_{\text {Prior }}$, Equation 6 (with $w_{\mathrm{I}}=1$ and $w_{\mathrm{T}}=0$ ) reduces to the earlier treatment of interim contrast (Equation 1). Thus, many of the analyses in Section 1 could be accomplished with the general model (Equation 6).

There are many simplifications in this development. Each of the sources of competition in Equation 6 may involve the same or different types of competing behavior, each with their own specific activation $a$ (see Haight \& Killeen, 1991, for examples), each competing with each other as well as with the target response. Alternate models of response competition that respect such dynamic interactions may better generalize this theory of contrast. The instantiation of the model in this paper assumes that stimulus control of the target response is essentially immediate. When it is not, it will come under slower stimulus control that may parallel or even lag that of the competing behavior. This can happen when the stimuli are not proximal to the target response in space or in time, or the target response has lower specific activation $(a)$ than some of the competing responses. In this case, no contrast, or non-monotonic contrast effects, or the appearance of induction, may occur (Schwartz, 1974). When stimuli are less than optimal, as may be the case for rats with colored lights over levers, initial contrast but terminal induction (generalization from the following schedule) may occur (Williams, 1990). When the $\mathrm{S}^{+}$is remote, various effects can occur (e.g., Schwartz, 1975). When stimuli are ineffective, we expect only induction, at least until the ensemble of responses comes under direct control by reinforcement frequency (Weatherly, Arthur, \& Lang, 2003). Some of these experimental niceties may be accommodated with changes in specific activations or time constants with the present models; others will require more general models. 


\section{Discussion}

The present is one among many theories of contrast. One of the earlier is Herrnstein's (1970). He formulated a general treatment of responding on the central premise that all behavior reflected choices among actions supported by scheduled and unscheduled reinforcers. His fundamental equation (\#13) is:

$$
P=\frac{k R}{R+R_{o}}
$$

Where $k$ is a free parameter giving the asymptotic response rate at high rates of reinforcement for the target response, and $R_{\mathrm{O}}$ is "aggregate reinforcement" from other sources"unscheduled, extraneous reinforcement". The responses supported by $R_{\mathrm{O}}$ are "interwoven" with the target response. Divide the numerator and denominator of Equation 7 by $R_{\mathrm{O}}$ to see the formal identity with Equation 2 when $A_{\mathrm{C}}$ is constant (see Equation B6). The ratio of Equation 7 for two different rates of scheduled reinforcement is a robust model of performance on concurrent schedules (Equation B7). But the Equations 2 and 7 diverge when it comes to interpretation of parameters, and the treatment of multiple schedules. Herrnstein (1970) generalized the above for multiple schedules as:

$$
P_{1}=\frac{k R_{1}}{R_{1}+m R_{2}+R_{o}}
$$

where $m$ is a constant representing the "degree of interaction across components". For concurrent schedules, $m \approx 1$, for single-key studies $m=0$, and for multiple schedules, $0<m<1$. Herrnstein footnoted that $R_{\mathrm{O}}$ might be expanded as $R_{\mathrm{O} 1}+m R_{\mathrm{O} 2}$. In some ways the present theory has been an expansion of that footnote. Herrnstein's hypothetical other reinforcement that supports other behaviors $\mathrm{B}_{\mathrm{C}}$ is identified in the present theory as the reinforcement for target responses (not exogenous reinforcement). Although key-pecking may be targeted, reinforcement is less a bullet 
than buckshot, as it also reinforces other responses, some competing, some variants of the nominal target (styles of responding), some irrelevant. His $R_{\mathrm{O} 2}$ is reinforcement in the ALT components; that in the preceding component can spill over (or, if that is a lower rate component, "chill" over) into the focal component causing initial contrast. $R_{\mathrm{O} 2}$ in the following component can reinforce (or reduce reinforcement of) competing responses in the focal component, causing terminal contrast. Herrnstein's $R_{\mathrm{O} 1}$, hypothetical reinforcement for other behavior in the focal component, is in the present theory the very reinforcers that support the target response in that component.

There are problems with Herrnstein's account (Edmon, 1978; McSweeney, 1980; Williams \& Wixted, 1986), but his invocation of reinforcers for competing behavior, either in the focal component, or in that and the alternate components, is a part of numerous theories of contrast, including the current one. What is different about the present account is that the $R_{\mathrm{O}}$ are identified not as alternate sources of reinforcement, but as the most powerful ones in the box - the ones that support the target response. That such reinforcers may support more than one class of behavior at the same time is well known (Catania, 1971; Davison \& Nevin, 1999; Fu \& Anderson, 2008; Johansen, Killeen, \& Sagvolden, 2007; Killeen, 1969; Staddon \& Zhang, 1991), as has their role in instigating and shaping adjunctive responses that might compete with the target response Killeen \& Pellón, 2013). It has also been known for some time that the stimuli associated with component change can reinforce or depress both operant and other responses (e.g., Terrace, 1972). The current paper is simply a Baconian exercise of adding together these facts.

This theory of behavioral contrast is a mechanistic one, as it hypostasizes a mechanism in occurent, typically unmeasured responses as the cause of contrast. These unwatched responses are the dark matter of our field. This perspective stands in contradistinction to molar theories that simply posit the induction of responses by molar correlations. Those are simpler, and by invoking 
action at a distance, need make no hypotheses concerning mechanism. Both are valuable approaches to this and other behavioral phenomena. They are complementary approaches, in the sense of Bohr's concept of complementarity (see, e,g,. Baum, 2012; French \& Kennedy, 1985; Killeen, 2001b) - in that they constitute different tradeoffs between parsimony and precision.

In analyzing phenomena it is useful to consider various classes of explanations, ones first suggested by Aristotle (see, e.g., Killeen, 2001a; Killeen, 2013): efficient causes, functions, mechanisms, and formal causes (maps onto forms of representation). It is the thesis of this paper that the efficient cause of behavioral contrast is signaled transition between contexts of differing reinforcement density. That transition is a necessary but not sufficient cause. It may cause target responses near the start of the focal component to suffer more or less competition from other responses that have been strengthened or weakened by the prior alternate component (initial contrast), and which persist for a while into the new component. These may disappear if and when the competing responses are gotten under control by stimuli signaling the focal component. Transition from the focal component to a following component is typically signaled by stimuli that may acquire conditioned reinforcing or punishing functions. These may differentially affect different classes of responses, in particular target and competing responses. This conditional effect will take longer to develop than initial contrast; if and when it does (Williams, 1990), it is called "the following schedule effect"-here terminal contrast.

The function of contrast is unclear. Control by context of reinforcement can be argued to have survival value, in that adequate contexts should be approached or avoided to the extent that alternate contexts are yet poorer or richer in resources. Alternatively, the contrast studied here may be a simple by-product of different classes of responses having differential associability with reinforcement, and differential ability to be brought under control by the types of stimuli used in these studies. In the "constraints on conditioning" debates of the last century, such differential 
associability was argued to be of significant evolutionary value, as also has the resulting phenomenon of peak shift (Lynn, Cnaani, \& Papaj, 2005).

The mechanisms of contrast are, at one level, the alternative responses that are hypothesized to compete with the target response for expression. At a deeper level, they are the fundamental processes of conditioning that are encoded in the nervous system. The formal causes of contrast are given by the various equations in this paper. Those equations are not to be seen as the final encapsulation of the theory: They are at best approximations, and at worst, ill posed. They evolved from many prior versions, and may continue to evolve. One earlier attempt involved subtractive competition rather than multiplicative competition. The present approach is arguably simpler and more transparent, and provides a marginally better fit to most of the data. But there is evidence for a subtractive process in response competition (Killeen \& Bizo, 1998; Reid \& Dale, 1983). It may be the case that a general treatment of other types of contrast will eventually require such a subtractive model.

Equations merely provide a mechanism to bring the richness of data to bear on the formulation of a theory, and the subsequent reformulation of its models as data permit or require. The logic of Equation 6 entails a dynamic process involving the stochastic emission of interim and target responses and the positive feedback of reinforcement on their interaction. Because of that, the emergence, dominance and subsidence of various responses will resemble a horse race, with different contenders trading places and eventually settling into a meta-stable pattern in the home stretch (Reid, et al., 1993). The adjunctive behaviors themselves may show initial contrast (Porter \& Allen, 1977). There are candidate models for such processes (Ferrell, 2012; Myerson \& Miezin, 1980; Reid \& Dale, 1983; Staddon, 1977a, 1982), and data to feed them (Innis, et al., 1983; Reid \& Dale, 1983; Reid, Vazquez, \& Rico, 1985). The relation to momentum theory (e.g., Nevin, 1992; Nevin, 1994) remains to be explored, as does the relation to Zentall and associates' 
demonstrations of what may be a novel contrast effect (e.g., Stagner \& Zentall, 2010; Zentall, 2007, 2010). Given the large number of trials necessary to establish it (Zentall \& Singer, 2007), it is consistent with a reading as terminal positive contrast. Equation 6 - the general model for contrast - may fit some data sets about equally well under the assumption of primarily initial contrast or primarily terminal contrast, with only experimental analysis able to resolve the source of the contrast. Such refinements or replacements will be a worthwhile hobby for those so inclined; the Mathematical Principles of Reinforcement provides one useful erector set: It provides models for the coupling of reinforcers to target or other responses, and all of the early work for this paper was grounded on it. Some investigators have been constructing useful refinements to it (e.g., Bittar, Del-Claro, Bittar, \& da Silva, 2012) and extensions of it (e.g., Bradshaw \& Killeen, 2012). But the most convincing test of the present theory will not be a more capacious model, but tests of the purported mechanisms at a qualitative level.

A fundamental aspect of the theory is that contrast arises from response competition. Interval reinforcement schedules are particularly susceptible to generating such inter-responses, because they reinforce any responses that occur before the final target response. It follows that variable ratio schedules, whose coupling of reinforcement to the target response is greater than for interval schedules, will not show as much contrast. At most, some spillover from a prior component may generate initial contrast, but that will decrease with training. Indeed, the higher rate of responding on ratio schedules occurs just because they support fewer competing responses than interval schedules (Killeen, 1969), so in some sense they emulate responding on VI schedules with strong positive contrast — contingencies and contrast being two different ways of reducing competition. It is a different case for fixed-ratio schedules, where temporal control provides periods of non-reinforcement that can serve as low local densities of reinforcement (Norborg, Osborne, \& Fantino, 1983). Contrast will, however, depend importantly on the 
topography of the target response, as that may have greater or less intrinsic associability with the particular reinforcer then do competing responses. Environments that restrict the opportunity for competing responses will show reduced contrast effects, just as they enhance the speed of learning the target response (Locurto, Travers, Terrace, \& Gibbon, 1980). Enriched environments will enhance contrast. Prior ratio schedules will generate less initial contrast than prior interval schedules, but the contingencies in the following schedule will have no effect on terminal contrast, as long as the distribution of reinforcers in the following schedule is comparable. (Wilkie (1971) reported positive contrast caused by delayed reinforcement in the alternate component, inconsistent with the present hypothesis — but Richards (1972) did not replicate that effect.)

The theory also predicts that initial and terminal contrast can be separately manipulated by clever fading in or out of discriminative stimuli (e.g., Terrace, 1972) before or after the focal component. "Errorless discrimination" (see, e.g, Arantes \& Machado, 2011) is sometimes associated with absence of contrast because, we argue, of the procedure's ability to obtain stimulus control over the competing behavior along with the target behavior, avoiding initial contrast, and then ending conditions before terminal contrast manifests. That narrow window is sometimes missed (Kodera \& Rilling, 1976). Of course, the nature and location of those stimuli will affect their differential associabilities with target versus competing responses. The amount of initial contrast in the focal component will depend on the strength of the coupling between reinforcement and target responses in both the focal and the prior component-well-coupled target responses such as those maintained by ratio schedules will leave little opportunity for the conditioning of much competing behavior. The presence or absence of a target response in the following schedule will have little effect on terminal contrast, as that depends on the reinforcing or punishing strength of the schedule transition, driven by differences in reinforcer density or 
quality. Similarly, the depression or elevation of target responding by contrast manipulations will not in itself change the incentive value of stimuli signaling that component (Williams, 1992).

Preference for a target stimulus will depend on the rate of reinforcement that it signals, primarily within that component, but also in the following schedule, if that is not too greatly removed (Killeen, 1982). By interposition of neutral stimuli, Williams and McDevitt (2001) were able to manipulate contrast without undermining the preference relations in complex multiple schedules.

Component transition is not restricted to multiple schedules. Inserting time-outs between components of VI 1 schedules produces substantial positive contrast in rats, which was reported as the effects of spaced vs. massed conditioning (Mackintosh, Little, \& Lord, 1972). The conditions for this experiment suggest that it was initial contrast that was occurring. The same one-minute time-outs, when inserted between VI 1 and EXT sufficiently separated them that no contrast was found - that is, no further elevation in response rates — whereas rates for the closely spaced components showed positive contrast (also see Wilton \& Clements, 1972).

A whole session constitutes one long component, for which both initial and terminal contrast are predicted. The former warm-up effects are well documented (e.g., Killeen \& Bizo, 1998). The post-session feeding effect (Bacotti, 1976; Smethells, Fox, Andrews, \& Reilly, 2012; Timberlake, Gawley, \& Lucas, 1987), and incentive contrast (Ettinger, McSweeney, \& Norman, 1981; Flaherty, 1999) may be manifestations of terminal contrast. In sum, it is possible that we are reaching the limit of what can be understood about an operant response by studying only the target response, and must begin the more difficult task of studying it in the context of other responses that are instigated by reinforcement (Bernstein \& Ebbesen, 1978; Findley, 1962; Herrnstein, 1977). It is time to study the dark matter - to un-tape the window on the Skinner box and watch our subjects behave - and to enlarge the number of terms in the three-term contingency to include other responses engaged by reinforcement as they abet or thwart the target response. 


\section{References}

Arantes, J., \& Machado, A. (2011). Errorless learning of a conditional temporal discrimination. Journal of the Experimental Analysis of Behavior, 95, 1-20.

Bacotti, A. V. (1976). Home cage feeding time controls responding under multiple schedules. Animal Learning \& Behavior, 4, 41-44.

Basseville, M., \& Nikiforov, I. V. (1993). Detection of abrupt changes: theory and application (Vol. 104): Prentice Hall Englewood Cliffs.

Baum, W. M. (2005). Understanding behaviorism: Behavior, culture, and evolution (2 ed.). Malden, MA: Blackwell Publishing.

Baum, W. M. (2012). Rethinking reinforcement: allocation, induction, and contingency. Journal of the Experimental Analysis of Behavior, 97, 101-124.

Bell, M. C., \& Williams, B. A. (2013). Conditioned reinforcement in chain schedules when time to reinforcement is held constant. Journal of the Experimental Analysis of Behavior, 99, 179-188.

Bernheim, J. W., \& Williams. (1967). Time-dependent contrast effects in a multiple schedule of food reinforcement. Journal of the Experimental Analysis of Behavior, 10, 243-249.

Bernstein, D. J., \& Ebbesen, E. B. (1978). Reinforcement and substitution in humans: a multiple response analysis. Journal of the Experimental Analysis of Behavior, 30, 243-253.

Bittar, E. G., Del-Claro, K., Bittar, L. G., \& da Silva, M. C. P. (2012). Towards a mathematical model of within-session operant responding. Journal of Experimental Psychology: Animal Behavior Processes, 38, 292-302.

Bloomfield, T. (1967). Behavioral contrast and relative reinforcement frequency in two multiple schedules. Journal of the Experimental Analysis of Behavior, 10, 151-158.

Blough, D. S. (1975). Steady state data and a quantitative model of operant generalization and discrimination. Journal of Experimental Psychology: Animal Behavior Processes, 104, 321. 
Bradshaw, C. M., \& Killeen, P. R. (2012). A theory of behaviour on progressive ratio schedules, with applications in behavioural pharmacology. Psychopharmacology, 222, 549-564.

Breland, K., \& Breland, M. (1961). The misbehavior of organisms. American Psychologist, 16, 681-684.

Buck, S. L., Rothstein, B., \& Williams, B. A. (1975). A re-examination of local contrast in multiple schedules. Journal of the Experimental Analysis of Behavior, 24, 291-301.

Catania, A. C. (1971). Reinforcement schedules: The role of responses preceding the one that produces the reinforcer. Journal of the Experimental Analysis of Behavior, 15, 271-287.

Catania, A. C. (1973). Self-inhibiting effects of reinforcement. Journal of the Experimental Analysis of Behavior, 19, 517-526.

Charman, L., \& Davison, M. (1982). On the effects of component durations and component reinforcement rates in multiple schedules. Journal of the Experimental Analysis of Behavior, 37, 417-439.

Cowie, S., Elliffe, D., \& Davison, M. (2013). Concurrent schedules: Discriminating reinforcerratio reversals at a fixed time after the previous reinforcer. Journal of the Experimental Analysis of Behavior, 100, 117-134.

Davison, M., \& Nevin, J. A. (1999). Stimuli, reinforcers and behavior: An integration. Journal of the Experimental Analysis of Behavior, 71, 439-482.

Dickinson, A., \& Balleine, B. (2002). The role of learning in the operation of motivational systems. In C. R. Gallisterl (Ed.), Stevens' handbook of experimental psychology (3rd ed., pp. 497-534). New York: John Wiley \& Sons.

Domjan, M. (1983). Biological constraints on instrumental and classical conditioning: Implications for general process theory. In G. H. Bower (Ed.), The psychology of learning and motivation: Advances in research and theory (Vol. 19, pp. 215-277). New York: Academic Press.

Donahoe, J. W., \& Palmer, D. C. (1988). Inhibition: A cautionary tale. Journal of the Experimental Analysis of Behavior, 50, 333-341. 
Dougan, J. D., McSweeney, F. K., \& Farmer-Dougan, V. (1986). Behavioral contrast in competitive and non-competitive environments. Journal of the Experimental Analysis of Behavior, 46, 185-197.

Edmon, E. L. (1978). Multiple schedule component duration: a reanalysis of Shimp and Wheatley (1971) and Todorov (1972). Journal of the Experimental Analysis of Behavior, 30, 239241.

Ettinger, R. H., McSweeney, F. K., \& Norman, W. D. (1981). Contrast and undermatching as a function of reinforcer duration and quality during multiple schedules. Journal of the Experimental Analysis of Behavior, 35, 271-282.

Ferrell, J. E., Jr. (2012). Bistability, bifurcations, and Waddington's epigenetic landscape. [Review]. Current Biology, 22, R458-466.

Fetterman, J. G., Killeen, P. R., \& Hall, S. (1998). Watching the clock. Behavioural Processes, $44,211-222$.

Findley, J. D. (1962). An experimental outline for building and exploring multi-operant repertoires. Journal of the Experimental Analysis of Behavior, 5, 113-166.

Flaherty, C. F. (1999). Incentive relativity: Cambridge University Press.

French, A. P., \& Kennedy, P. J. (Eds.). (1985). Niels Bohr: A centenary volume. Cambridge, MA: Harvard University Press.

Fu, W. T., \& Anderson, J. R. (2008). Solving the credit assignment problem: explicit and implicit learning of action sequences with probabilistic outcomes. Psychological Research, 72, 321-330.

Garcia, J., McGowan, B. K., \& Green, K. F. (1972). Biological constraints on conditioning. Classical conditioning II: Current research and theory, 3-27.

Gibbon, J. (1977). Scalar expectancy theory and Weber's law in animal timing. Psychological Review, 84, 279-325.

Haight, P. A., \& Killeen, P. R. (1991). Adjunctive behavior in multiple schedules of reinforcement. Animal Learning \& Behavior, 19, 257-263. 
Halliday, M., \& Boakes, R. (1971). Behavioral contrast and response independent reinforcement. Journal of the Experimental Analysis of Behavior, 16, 429-434.

Hemmes, N. S. (1973). Behavioral contrast in pigeons depends upon the operant. Journal of Comparative and Physiological Psychology, 85, 171-178.

Herrnstein, R. J. (1970). On the law of effect. Journal of the Experimental Analysis of Behavior, $13,243-266$.

Herrnstein, R. J. (1977). The evolution of behaviorism. American Psychologist, 32, 593-603.

Hinson, J. M., \& Staddon, J. E. R. (1978). Behavioral competition: A mechanism for schedule interactions. Science, 202, 432-434.

Hinson, J. M., \& Staddon, J. E. R. (1981). Some temporal properties of local contrast. Behaviour Analysis Letters, 1, 275-281.

Hysteresis. (2014, July 18). In Wikipedia, The Free Encyclopedia. Retrieved 7:53, July 27, 2014, from http://en.wikipedia.org/w/index.php?title=Hysteresis\&oldid=605831039.

Innis, N. K., Simmelhag-Grant, V. L., \& Staddon, J. E. R. (1983). Behavior induced by periodic food delivery: The effects of interfood interval. Journal of the Experimental Analysis of Behavior, 39, 309-322.

Johansen, E. B., Killeen, P. R., \& Sagvolden, T. (2007). Behavioral variability, elimination of responses, and delay-of-reinforcement gradients in SHR and WKY rats. Behavioral and Brain Functions, 60.

Killeen, P. R. (1968). On the measurement of reinforcement frequency in the study of preference. Journal of the Experimental Analysis of Behavior, 11, 263-269.

Killeen, P. R. (1969). Reinforcement frequency and contingency as factors in fixed-ratio behavior. Journal of the Experimental Analysis of Behavior, 12, 391-395.

Killeen, P. R. (1975). On the temporal control of behavior. Psychological Review, 82, 89-115.

Killeen, P. R. (1979). Arousal: Its genesis, modulation, and extinction. In M. D. Zeiler \& P. Harzem (Eds.), Advances in analysis of behavior: Vol. 1. Reinforcement and the organization of behavior (pp. 31-78). Chichester, England: Wiley. 
Killeen, P. R. (1981). Averaging theory. In C. M. Bradshaw, E. Szabadi \& C. F. Lowe (Eds.), Quantification of steady-state operant behaviour (pp. 21-34). Amsterdam: Elsevier.

Killeen, P. R. (1982). Incentive theory II: Models for choice. Journal of the Experimental Analysis of Behavior, 38, 217-232.

Killeen, P. R. (1994). Mathematical principles of reinforcement. Behavioral and Brain Sciences, $17,105-172$.

Killeen, P. R. (1998). The first principle of reinforcement. In C. D. L. Wynne \& J. E. R. Staddon (Eds.), Models of Action: Mechanisms for Adaptive Behavior (pp. 127-156). Mahwah, NJ: Lawrence Erlbaum Associates.

Killeen, P. R. (2001a). The four causes of behavior. Current Directions in Psychological Science, $10,136-140$.

Killeen, P. R. (2001b). Modeling games from the $20^{\text {th }}$ century. Behavioural Processes, 54, 33-52.

Killeen, P. R. (2013). The structure of scientific evolution. The Behavior Analyst, 36, 325-344.

Killeen, P. R., \& Bizo, L. A. (1998). The mechanics of reinforcement. Psychonomic Bulletin \& Review, 5, 221-238.

Killeen, P. R., Hall, S. S., Reilly, M. P., \& Kettle, L. C. (2002). Molecular analyses of the principal components of response strength. Journal of the Experimental Analysis of Behavior, 78, 127-160.

Killeen, P. R., Hanson, S. J., \& Osborne, S. R. (1978). Arousal: Its genesis and manifestation as response rate. Psychological Review, 85, 571-581.

Killeen, P. R., \& Pellón, R. (2013). Adjunctive behaviors are operants. Learning \& Behavior, 41, $1-24$.

Killeen, P. R., Sanabria, F., \& Dolgov, I. (2009). The dynamics of conditioning and extinction. Journal of Experimental Psychology: Animal Behavior Processes, 35, 447-472.

Killeen, P. R., \& Sitomer, M. T. (2003). MPR. Behavioural Processes, 62, 49-64.

King, G. R., \& McSweeney, F. K. (1987). Contrast during multiple schedules with different component response requirements. Animal Learning \& Behavior, 15, 97-104. 
Kodera, T. L., \& Rilling, M. (1976). Procedural antecedents of behavioral contrast: a reexamination of errorless learning. Journal of the Experimental Analysis of Behavior, 25, $27-42$.

Laties, V. G., Weiss, B., \& Weiss, A. B. (1969). Further observations on overt "mediating" behavior and the discrimination of time. Journal of the Experimental Analysis of Behavior, 12, 43-57.

Lieberman, D. A., Davidson, F. H., \& Thomas, G. V. (1985). Marking in pigeons: The role of memory in delayed reinforcement. Journal of Experimental Psychology: Animal Behavior Processes, 11, 611-624.

Locurto, C. M., Travers, T., Terrace, H. S., \& Gibbon, J. (1980). Physical restraint produces rapid acquisition of the pigeon's key peck. Journal of the Experimental Analysis of Behavior, $34,13-21$.

López-Crespo, G., Rodríguez, M., Pellón, R., \& Flores, P. (2004). Acquisition of scheduleinduced polydipsia by rats in proximity to upcoming food delivery. Learning $\&$ Behavior, $32,491-499$.

Lynn, S. K., Cnaani, J., \& Papaj, D. R. (2005). Peak shift discrimination learning as a mechanism of signal evolution. Evolution, 59, 1300-1305.

Machado, A. (2014a). This is the solution (Eq. C1). In P. R. Killeen (Ed.). A theory of behavioral conrast: Society for the Experimental Analysis of Behavior.

Machado, A. (2014b). Try this (Eq. C2). In P. R. Killeen (Ed.). A theory of behavioral contrast: Society for the Experimental Analysis of Behavior.

Mackintosh, N. J. (1974). The psychology of animal learning. New York: Academic Press.

Mackintosh, N. J., Little, L., \& Lord, J. (1972). Some determinants of behavioral contrast in pigeons and rats. Learning and Motivation, 3, 148-161.

McFarland, D. J. (1971). Feedback mechanisms in animal behaviour. New York: Academic Press. 
McLean, A. P., \& White, K. G. (1983). Temporal constraint on choice: Sensitivity and bias in multiple schedules. Journal of the Experimental Analysis of Behavior, 39, 405-426.

McSweeney, F. K. (1980). Differences between rates of responding emitted during simple and multiple schedules. Animal Learning \& Behavior, 8, 392-400.

McSweeney, F. K. (1982). Positive and negative contrast as a function of component duration for key pecking and treadle pressing. Journal of the Experimental Analysis of Behavior, 37, 281-293.

McSweeney, F. K. (1983). Positive behavioral contrast when pigeons press treadles during multiple schedules. Journal of the Experimental Analysis of Behavior, 39, 149-156.

McSweeney, F. K. (1987). Suppression by reinforcement, a model for multiple-schedule contrast. Behavioural Processes, 15, 191-209.

McSweeney, F. K., Dougan, J. D., Higa, J., \& Farmer, V. A. (1986). Behavioral contrast as a function of component duration and baseline rate of reinforcement. Animal Learning \& Behavior, 14, 173-183.

Mehra, J. (1994). The beat of a different drum: the life and science of Richard Feynman: Clarendon Press Oxford.

Myerson, J., \& Miezin, F. M. (1980). The kinetics of choice: An operant systems analysis. Psychological Review, 87, 160-174.

Nevin, J. A. (1992). An integrative model for the study of behavioral momentum. Journal of the Experimental Analysis of Behavior, 57, 301-316.

Nevin, J. A. (1994). Extension to multiple schedules: Some surprising (and accurate) predictions. Behavioral and Brain Sciences, 17, 145-146.

Nevin, J. A., \& Shettleworth, S. J. (1966). An analysis of contrast effects in multiple schedules. Journal of the Experimental Analysis of Behavior, 9, 305-315.

Nevin, J. A., Smith, L. D., \& Roberts, J. (1987). Does contingent reinforcement strengthen operant behavior? Journal of the Experimental Analysis of Behavior, 48, 17-33. 
Norborg, J., Osborne, S., \& Fantino, E. (1983). Duration of components and response rates on multiple fixed-ratio schedules. Animal Learning \& Behavior, 11, 51-59.

Osborne, S. R., \& Killeen, P. R. (1977). Temporal properties of responding during stimuli that preceed response-independent food. Learning and Motivation, 8, 533-550.

Patterson, A. E., \& Boakes, R. A. (2012). Interval, blocking and marking effects during the development of schedule-induced drinking in rats. Journal of Experimental Psychology: Animal Behavior Processes, 303-314.

Pear, J. J. (1985). Spatiotemporal patterns of behavior produced by variable-interval schedules of reinforcement. Journal of the Experimental Analysis of Behavior, 44, 217-231.

Pellón, R., \& Pérez-Padilla, Á. (2013). Response-food delay gradients for lever pressing and schedule-induced licking in rats. Learning \& Behavior, 41, 218-227.

Porter, J. H., \& Allen, J. D. (1977). Schedule-induced polydipsia contrast in the rat. Animal Learning \& Behavior, 5, 184-192.

Rachlin, H. (1973). Contrast and matching. Psychological Review, 80, 217-234.

Rachlin, H. (1978). A molar theory of reinforcement schedules. Journal of the Experimental Analysis of Behavior, 30, 345-360.

Rachlin, H. (1988). Molar behaviorism. In D. B. Fishman, F. Rotgers \& C. M. Franks (Eds.), Paradigms in behavior therapy: Present and promise (pp. 77-105). New York: Springer.

Reid, A. K., \& Allen, D. L. (1998). A parsimonious alternative to the pacemaker/accumulator process in animal timing. Behavioural Processes, 44, 119-125.

Reid, A. K., Bachá, G., \& Morán, C. (1993). The temporal organization of behavior on periodic food schedules. Journal of the Experimental Analysis of Behavior, 59, 1-27.

Reid, A. K., \& Dale, R. H. I. (1983). Dynamic effects of food magnitude on interim-terminal interaction. Journal of the Experimental Analysis of Behavior, 39, 135-148.

Reid, A. K., Vazquez, P. P., \& Rico, J. A. (1985). Schedule induction and the temporal distributions of adjunctive behavior on periodic water schedules. Learning \& Behavior, $13,321-326$. 
Reynolds, G. S. (1961). Behavioral contrast. Journal of the Experimental Analysis of Behavior, 4, $57-71$.

Richards, R. W. (1972). Reinforcement delay: Some effects on behavioral contrast. Journal of the Experimental Analysis of Behavior, 17, 381-394.

Roper, T. J. (1978). Diversity and substitutability of adjunctive activities under fixed-interval schedules of food reinforcement. Journal of the Experimental Analysis of Behavior, 30, $83-96$.

Royalty, P., Williams, B. A., \& Fantino, E. (1987). Effects of delayed conditioned reinforcement in chain schedules. Journal of the Experimental Analysis of Behavior, 47, 41-56.

Schwartz, B. (1974). Behavioral contrast in the pigeon depends upon the location of the stimulus. Bulletin of the Psychonomic Society, 3, 365-368.

Schwartz, B. (1975). Discriminative stimulus location as a determinant of positive and negative behavioral contrast in the pigeon. Journal of the Experimental Analysis of Behavior, 23, 23-167.

Seligman, M. E. P. (1970). On the generality of the laws of learning. Psychological Review, 77, 406-418.

Shettleworth, S. J. (1972). Constraints on learning. Advances in the Study of Behavior, 4, 1-68.

Shimp, C. P., \& Wheatley, K. L. (1971). Matching to relative reinforcement frequency in multiple schedules with a short component duration. Journal of the Experimental Analysis of Behavior, 15, 205-210.

Smethells, J. R., Fox, A. T., Andrews, J. J., \& Reilly, M. P. (2012). Immediate postsession feeding reduces operant responding in rats. Journal of the Experimental Analysis of Behavior, 97, 203-214.

Staddon, J. E. R. (1973). On the notion of cause, with applications to behaviorism. Behaviorism, 1, 25-63.

Staddon, J. E. R. (1977a). On Herrnstein's equation and related forms. Journal of the Experimental Analysis of Behavior, 28, 163-170. 
Staddon, J. E. R. (1977b). Schedule-induced behavior. In W. K. Honig \& J. E. R. Staddon (Eds.), Handbook of operant behavior (pp. 125-152). Englewood Clifffs, NJ: Prentice-Hall.

Staddon, J. E. R. (1982). Behavioral competition, contrast and matching. In M. L. Commons, R. J. Herrnstein \& H. Rachlin (Eds.), Quantitative analyses of operant behavior: Matching and maximizing accounts (Vol. 2, pp. 243-261). Cambridge, MA: Ballinger.

Staddon, J. E. R., \& Zhang, Y. (1991). On the assignment-of-credit problem in operant learning. In M. Commons, S. Grossberg \& J. E. R. Staddon (Eds.), Neural network models of conditioning and action (pp. 279-293). Hillsdale, NJ: Lawrence Erlbaum Associates, Inc.

Stagner, J. P., \& Zentall, T. R. (2010). Suboptimal choice behavior by pigeons. Psychonomic Bulletin \& Review, 17, 412-416.

Terrace, H. S. (1972). By-products of discrimination learning. In G. H. Bower (Ed.), Psychology of Learning and Motivation (Vol. 5, pp. 195-265). New York: Academic Press.

Thomas, D. R., Windell, B. T., Bakke, I., Kreye, J., Kimose, E., \& Aposhyan, H. (1985). Longterm memory in pigeons: I. The role of discrimination problem difficulty assessed by reacquisition measures II. The role of stimulus modality assessed by generalization slope. Learning and Motivation, 16, 464-477.

Timberlake, W., Gawley, D. J., \& Lucas, G. A. (1987). Time horizons in rats foraging for food in temporally separated patches. Journal of Experimental Psychology: Animal Behavior Processes, 13, 302-309.

Timberlake, W., Wahl, G., \& King, D. A. (1982). Stimulus and response contingencies in the misbehavior of rats. Journal of Experimental Psychology: Animal Behavior Processes, 8, $62-85$.

Todorov, J. C. (1972). Component duration and relative response rates in multiple schedules. Journal of the Experimental Analysis of Behavior, 17, 45-49.

Tonneau, F. (2013). Neorealism: Unifying cognition and environment. Review of General Psychology, 17, 237-242. 
Weatherly, J. N., Arthur, E. I., \& Lang, K. K. (2003). The effect of type of behavior on behavior change caused by type of upcoming food substance. Learning and Motivation, 34, 325340 .

Westfall, R. S. (1971). The construction of modern science: Mechanisms and mechanics. New York: Cambridge University Press.

Wilcox, R. R. (1998). How many discoveries have been lost by ignoring modern statistical methods? American Psychologist, 53, 300-314.

Wilkie, D. M. (1971). Delayed reinforcement in a multiple schedule. Journal of the Experimental Analysis of Behavior, 16, 233-239.

Williams, B. A. (1976). Behavioral contrast as a function of the temporal location of reinforcement. Journal of the Experimental Analysis of Behavior, 26, 57-64.

Williams, B. A. (1979). Contrast, component duration, and the following schedule of reinforcement. Journal of Experimental Psychology: Animal Behavior Processes, 5, 379396.

Williams, B. A. (1980). Contrast, signaled reinforcement, and the relative law of effect. The American Journal of Psychology, 95, 617-629.

Williams, B. A. (1981). The following schedule of reinforcement as a fundamental determinant of steady state contrast in multiple schedules. Journal of the Experimental Analysis of Behavior, 35, 293-310.

Williams, B. A. (1983). Another look at contrast in multiple schedules. Journal of the Experimental Analysis of Behavior, 39, 345-384.

Williams, B. A. (1988). Component transition and anticipatory contrast. Bulletin of the Psychonomic Society, 26, 269-272.

Williams, B. A. (1988). The effects of stimulus similarity on different types of behavioral contrast. Animal Learning \& Behavior, 16, 206-216.

Williams, B. A. (1989). Component duration effects in multiple schedules. Animal Learning \& Behavior, 17, 223-233. 
Williams, B. A. (1990). Absence of anticipatory contrast in rats trained on multiple schedules. Journal of the Experimental Analysis of Behavior, 53, 395-407.

Williams, B. A. (1991). Marking and bridging versus conditioned reinforcement. Animal Learning \& Behavior, 19, 264-269.

Williams, B. A. (1992). Inverse relations between preference and contrast. Journal of the Experimental Analysis of Behavior, 58, 303-312.

Williams, B. A. (1994). Conditioned reinforcement: Neglected or outmoded explanatory construct? Psychonomic Bulletin \& Review, 1, 457-475.

Williams, B. A. (2002). Behavioral contrast redux. Animal Learning \& Behavior, 30, 1-20.

Williams, B. A., \& Dunn, R. (1991). Preference for conditioned reinforcement. Journal of the Experimental Analysis of Behavior, 55, 37-46.

Williams, B. A., \& McDevitt, M. A. (2001). Competing sources of stimulus value in anticipatory contrast. Animal Learning \& Behavior, 29, 302-310.

Williams, B. A., \& Royalty, P. (1990). Conditioned reinforcement versus time to reinforcement in chain schedules. Journal of the Experimental Analysis of Behavior, 53, 381-393.

Williams, B. A., \& Wixted, J. T. (1986). An equation for behavioral contrast. Journal of the Experimental Analysis of Behavior, 45, 47-62.

Wilton, R. N., \& Clements, R. O. (1971). Behavioral contrast as a function of the duration of an immediately preceding period of extinction. Journal of the Experimental Analysis of Behavior, 16, 425-428.

Wilton, R. N., \& Clements, R. O. (1972). A failure to demonstrate behavioral contrast when the $\mathrm{S}+$ and $\mathrm{S}$ - components of a discrimination schedule are separated by about 23 hours. Psychonomic Science, 28, 137-139.

Zentall, T. R. (2007). Reinforcers Following Greater Effort are Preferred: A Within-Trial Contrast Effect. Behavior Analyst Today, 8, 512-527.

Zentall, T. R. (2010). Justification of Effort by Humans and Pigeons. Current Directions in Psychological Science, 19, 296-300. 
Zentall, T. R., \& Singer, R. A. (2007). Within-trial contrast: pigeons prefer conditioned reinforcers that follow a relatively more rather than a less aversive event. Journal of the Experimental Analysis of Behavior, 88, 131-149.

Author note: This paper could not have been right without the astute commentary and help I received from Armando Machado, Ben Williams and Alliston Reid. It could not have been written at all without the rich data that Williams in particular contributed to this literature. AM checked all the math, all of the fits to data, suggested improvements, and advised on better layouts for the figures. All deserve to be co-authors. And although they did their utmost to save me from error, they should not be held liable for any errors I committed despite their help. I also thank Matt Bell for many insightful comments on an earlier draft. 


\section{Appendices}

\section{Appendix A: Response strength-Just skip ahead to A3 and the paragraphs that follow it.}

Stimuli associated with changes in reinforcement density do not necessarily move the animal as a whole from one coherent behavioral state to another, but rather control the emission of responses. They modulate operant classes. Some responses such as the target response of keypecking may be under good control by component changes signaled by lights on the keys, leverpressing signaled by colored lights less so, and some responses, such as changes in orientation, pecking at the floor, grooming, pacing, turning, off-key pecking, and adjunctive and interim responses in general, may be under poor or negligible control by key colors. They may nonetheless come under the control of changes in rates of reinforcement in those components, or even of the context that involves changes in the target response. What formal models can describe this process?

A1. Biological. One mechanism for sensitivity to reinforcement density is general changes in arousal level. Arousal theory has been applied to reinforcement schedules (Killeen, 1979; Killeen, Hanson, \& Osborne, 1978), and forms one of the three principles of the Mathematical Principles of Reinforcement (MPR) (Killeen, 1998; Killeen \& Sitomer, 2003). Although the formal model for accumulation and decumulation of arousal applies (with continuing refinement, such as that by Bittar, et al., 2012), and directly yields a version of Equation 1 in the text, its time constants are generally too long to mediate the changes seen in initial contrast.

A2. Logical. How would a smart rat or pigeon, one equipped with all of the computational ability of those studied by Gallistel, be responsive to a change in reinforcement density absent control by visual or auditory stimuli? Change-point detection in the density of random processes, such as those approximated by VI schedules, can be a subtle issue (Basseville \& Nikiforov, 1993). Let us take a simple approach, and ask what is the likelihood that an inter-reinforcement 
interval $t$ came from a component with mean interval $\mu_{1}$ (mu-sub-one, essentially the VI value) or another with mean interval $\mu_{2}$ ? Random-interval (RI) schedules, the idealization of VI schedules, are constant probability distributions in which the probability of an inter-food interval (IFI) of length $t$ is $e^{-t / \mu} / \tau$ where $\tau$ is the mean of the RI schedule. It follows that the relative likelihoodthe ratio of the two likelihoods for RI schedules $S_{1}$ and $S_{2}$ with means $\mu_{1}$ and $\mu_{2}$-is $l\left(S_{1} / S_{2}\right)=\left(e^{-t / \mu_{1}} / e^{-t / \mu_{2}}\right)\left(\mu_{2} / \mu_{1}\right)$. For reasons of symmetry, it is the log-likelihood that is typically used, and the log-likelihood of these two schedules is the natural logarithm of the right-hand side: $t\left(1 / \mu_{2}-1 / \mu_{1}\right)+\ln \left(\mu_{2} / \mu_{1}\right)$. Thus the log-likelihood of schedule $\mathrm{S}_{1}$ relative to $\mathrm{S}_{2}$ is a linear function of the length of the IFI $t$. The diagnosticity of the IFI is proportional to the difference in the rates of reinforcement between the two end states. Thus our dumb bird can act smart simply by paying attention to the IFI, which it presumably has been doing all along in any case. But the IFI is as random as a Poisson process can be, and it is not generally in the bird's interest to be randomly oscillating between two different behavioral patterns. Furthermore, the first IFI in the changed component will be a mixture of the two densities. The bird should collect more data before changing behavior. The easiest way to do that is to consider more than one interval, perhaps with the biologically simplest of averaging schemes, the exponentially-weighted moving average (Killeen, 1981). This will amplify the diagnosticity while slowing responsivity. But if the animal waits for two IFIs to evaluate where it is, in extinction the second will never come, and its evaluation will be stuck forever at the last IFI pair. A few absurd proposals to that effect exist (e.g., Killeen, 1998; Killeen, et al., 2009), not worth further countenance here. These complexities counsel weighing the next assay before further mining this vein.

A3. Dynamics. Working in the decade that the above models of Staddon, and Myerson and Miezin appeared, Don Blough (1975) published a model of dimensional contrast based on the familiar linear approach-to-asymptote (“error correction") model: 


$$
\Delta v_{i}=\gamma_{S_{i}} \beta\left(\lambda-v_{S_{i}}\right)
$$

On the left is the change in associative strength of stimulus element $i$, the $\gamma$ (gammas) are generalization factors for stimulus elements $S_{\mathrm{i}}, \beta$ (beta) is a learning rate parameter, $\lambda$ (lambda) the equilibrium level that would be maintained by reinforcement conditions, and $v_{S_{i}}$ the strength of element $S_{\mathrm{i}}$ at the start of the trial. Although construed in terms of trials, learning and associative strength, the same equation provides a model of the adjustment of strength through a trial, with lambda being the equilibrium strength that would be sustained for that stimulus/response/reinforcement triplet.

Rewriting A1 as a differential function of time, not trial, and integrating gives:

$$
\begin{aligned}
& v_{T}=\lambda_{T}-\left(\lambda_{T}-v_{T}^{\prime}\right) e^{-t / \tau_{T}} \\
& v_{O}=\lambda_{O}-\left(\lambda_{O}-v_{O}^{\prime}\right) e^{-t / \tau_{O}}
\end{aligned}
$$

for target and other responses. Equations A9 are exponentially weighted moving averages that update $v_{\mathrm{T}}$, the association of the target response with the signaled reinforcement schedule. $\lambda_{\mathrm{T}}$ is the asymptotic level of association, and $v^{\prime}$ is the association at the start of the component. In most of the cases studied in this paper we are not concerned with acquisition or generalization, so the rate constants $\gamma_{\mathrm{Si}} \beta$ are replaced with their reciprocal, the time constant $\tau$ (tau), tagged for target and other responses. The discriminative stimuli for the target response are typically distinctive, so we further assume that $v_{\mathrm{T}}$ has closely approached its asymptote $\lambda_{\mathrm{T}}$, noting in the text where that may not be the case.

Blough's associative values v correspond to the inverse of Davison and Nevin's (1999) parameter $d_{\mathrm{r}}$ which represents the indiscriminability of the relation between reinforcement and behavior. We interpret them as measures of response strength, and put their asymptotic value 
proportional to the rate of reinforcement that they signal $\lambda=A=\operatorname{ar}$ (see, for example, Killeen $\&$ Bizo, 1998, Equation 1). Rewriting Equation A2:

$$
A(t)=e^{-t / \tau} A_{\text {Prior }}+\left(1-e^{-t / \tau}\right) a r_{\text {Current }}
$$

$A(t)$ is the response strength at time $t, A_{\text {Prior }}$ is the strength just before the change-point, $a r_{\text {Current }}=A_{\text {Current }}$ is its current asymptotic value, and $\tau$ is the time constant of adjustment. These accounts are kept separately for target and other responses. It is assumed, however, that the target response quickly comes to its asymptotic value under good stimulus control, so that $A_{\mathrm{T}}(t)=$ $a_{\mathrm{T}} r_{\text {Current. }}$ Equation A3 is flagged for competing responses, slower to come to asymptote, and sent forward as Equation 1 in the body of the text. It constitutes a the central term in MPR's (Killeen, 1994; Killeen \& Sitomer, 2003) coupling coefficient.

Whereas linear operator models such as A3 are typically used in our literature as learning models, they are general tools that capture the step response of the simplest, first order control systems. In particular, Equation A3 is of the same form as Newton's law of cooling. Even in the current use they may be understood as describing a kind of learning, but it is a short-term learning about and adjustment to a new reinforcement context. This less-than-immediate effect of the past on current behavior in the present exemplifies hysteresis.

\section{Appendix B: From strength to rate}

From MPR (e.g., Killeen, 1994, Equation B7; 1998, Equation 8), in the absence of competing responses, response rate is:

$$
B=\frac{A}{\delta(1+A)} \text {. }
$$


Multiplying Equation B1 by $\delta$ gives the proportion of a unit time interval occupied in a response class, such as the measured target responses.

$$
p\left(\mathrm{~B}_{\mathrm{T}}\right)=\frac{A_{\mathrm{T}}}{1+A_{\mathrm{T}}}
$$

This assumes the absence of competing responses. To account for competition, MPR introduced the coupling coefficient. If that can be computed a priori, as for some schedules, it is denoted $\zeta$; otherwise, it is inferred post hoc and denoted $C$. The coupling coefficient gives the association between the target response and reinforcement. It is the complement of the probability that competing behaviors will occur and be reinforced, $1-p\left(\mathrm{~B}_{\mathrm{C}}\right)$. The probability of being engaged in the target response and not engaged in effective competing responses is:

$$
\widehat{p}\left(B_{T}\right)=p\left(B_{T}\right)\left(1-p\left(B_{C}\right)\right)
$$

Adding the factor $C$ to Equation B2and expanding it gives:

$$
\begin{aligned}
& \hat{p}\left(B_{\mathrm{T}}\right)=\frac{A_{\mathrm{T}}}{1+A_{\mathrm{T}}} C \\
& \hat{p}\left(B_{\mathrm{T}}\right)=\frac{A_{\mathrm{T}}}{1+A_{\mathrm{T}}}\left(1-p\left(B_{\mathrm{C}}\right)\right) \\
& \hat{p}\left(B_{\mathrm{T}}\right)=\frac{A_{\mathrm{T}}}{1+A_{\mathrm{T}}}\left(1-\frac{A_{\mathrm{C}}}{1+A_{\mathrm{C}}}\right)
\end{aligned}
$$

We may then predict response rate by scaling the net probability to the maximum attainable rate:

$$
B_{T}=k \frac{A_{T}}{1+A_{T}}\left(1-\frac{A_{C}}{1+A_{C}}\right)
$$


where $k=1 / \delta$ is the maximum response rate that can be made by that subject on that interface. Equation B5 is sent back to the text as Equation 2, where $A_{\mathrm{C}}$ is expanded with the hysteresis model.

Notice that if $A_{\mathrm{C}}$ is constant the parenthetical of Equation B5 may be absorbed into $k$. Then rewrite Equation B4 as:

$$
B_{T}=k^{\prime} \frac{a_{T} r}{1+a_{T} r}
$$

let $r_{\mathrm{o}}=1 / a_{\mathrm{T}}$, and Herrnstein's hyperbola manifests:

$$
B_{T}=\frac{k^{\prime} r}{r_{o}+r} \text {. }
$$

A ratio of Equation B6 for two rates of reinforcement yields McLean and White's (1983) key Equation 7 for multiple schedules:

$$
\frac{B_{\mathrm{A}}}{B_{\mathrm{B}}}=\frac{r_{\mathrm{A}}}{r_{\mathrm{B}}} \cdot \frac{r_{\mathrm{B}}+1 / r_{\mathrm{o}}}{r_{\mathrm{A}}+1 / r_{\mathrm{o}}} .
$$

\section{Appendix C: Fitting data}

All predictions were achieved by minimizing the sum of the squared deviation between model and data. Minimizing the sum of the absolute deviations is a more robust method that has much to recommend it, as none of the data were trimmed (Wilcox, 1998), but it was deemed prudent to use the more familiar cost function, the sum of errors squared. In Figures 1 and 2, the model was fitted to the time at the midpoints of the bins. In Figure 4, the bins were too large (3 
$\mathrm{min}$ ) to make that point representative, so predictions were made at $30 \mathrm{~s}$ intervals through the first 3 min of the following schedule and averaged, and this was repeated for the second 3 min.

A more powerful approach is to compute the average strength of competing responses to predict molar contrast. This is:

$$
\bar{A}_{\mathrm{C}}=A_{\mathrm{C}, \text { Curr }}+\left(A_{\mathrm{C}, \text { Prior }}-A_{\mathrm{C}, \text { Curr }}\right) \tanh \left(\frac{T}{2 \tau}\right) \frac{\tau}{T}
$$

where $A_{\text {Curr }}=a_{\mathrm{C}} r_{\text {Current }}, \mathrm{A}_{\text {Prior }}=a_{\mathrm{C}} r_{\text {Prior }}$, tanh is the hyperbolic tangent function, and $T$ is the duration of the components (Machado, 2014a).

The average competing response strength may be used in place of the instantaneous strength $A_{\mathrm{C}}$ in Equation 2 to predict molar response rate when both ALT and Focal components are of duration $T$. With this instantiation, Equation 2 gives the formal predictions for molar contrast, averaged over a whole interval, when that is due primarily to initial contrast. Note that for long components or fast time constants, the fraction $\tau / T$ becomes small, and the average strength of competing responses becomes approximately equal to the support for them in the current component, $A_{\text {Curr }}$.

The parameters $k, a_{\mathrm{T}}$, and $a_{\mathrm{C}}$ are somewhat collinear: Increases in $k$ will do some of the work of increases in $a_{\mathrm{T}}$, and increases in the latter may do some of the work of decreases in the last. Therefore the value of $k$ was capped at its largest realistically possible value 300 responses per minute (sometimes at 240 per min if the former misrepresented the data), and $a_{\mathrm{T}}$ at 500 . The parameters in Tables 1 and 2 should therefore be understood as carrying substantial implicit error bars.

To compute the strength of competing responses at the beginning of a component, one may simply iterate the model over 3 or 4 alterations of the components for Equation 1 to reach its stable values. Alternatively, when component durations are equal (Machado, 2014b): 


$$
A_{\mathrm{C}}(0)=w a_{\mathrm{C}} r_{\text {Prior }}+(1-w) a_{\mathrm{C}} r_{\text {Current }}
$$

with

$$
w=\left(1+e^{-T / \tau}\right)^{-1}
$$

At long component durations $T$ (relative to the value of $\tau$ ) $w \rightarrow 1$, and so competition is at its maximum (for prior rich components) or minimum (for prior lean components) value of $A_{\mathrm{C}}(0) \approx a_{\mathrm{C}} r_{\text {Prior }}$

At short component durations $w \rightarrow 1 / 2$, competition will reach an equilibrium equal to the average of that normally sustained by each component: the reinforcement rate sustaining competition is just a schmear of the two: $A_{\mathrm{C}}(0) \approx a_{\mathrm{C}}\left(r_{\text {Prior }}+r_{\text {Current }}\right) / 2$. Concurrent schedules typically have short component durations, making $A_{\mathrm{C}}$ approximately equal for each, so that the competition term cancels out of a relative measure, and Equation B7 becomes this model's prediction of relative response rates on concurrents.

\footnotetext{
${ }^{\mathrm{i}}$ In keeping with tradition the temporal unit for VI schedules is minutes unless otherwise noted.
} 